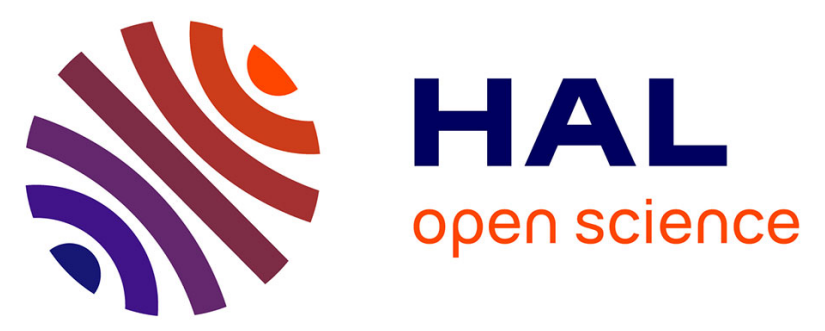

\title{
A large panel of chicken cells are invaded in vivo by Salmonella Typhimurium even when depleted of all known invasion factors
}

Sylvie M Roche, Sébastien Holbert, Yves Le Vern, Christelle Rossignol, Aurore Rossignol, Philippe Velge, Isabelle Virlogeux-Payant

\section{To cite this version:}

Sylvie M Roche, Sébastien Holbert, Yves Le Vern, Christelle Rossignol, Aurore Rossignol, et al.. A large panel of chicken cells are invaded in vivo by Salmonella Typhimurium even when depleted of all known invasion factors. Open Biology, 2021, 11 (11), 15 p. 10.1098/rsob.210117 . hal-03441032

\section{HAL Id: hal-03441032 \\ https://hal.inrae.fr/hal-03441032}

Submitted on 22 Nov 2021

HAL is a multi-disciplinary open access archive for the deposit and dissemination of scientific research documents, whether they are published or not. The documents may come from teaching and research institutions in France or abroad, or from public or private research centers.
L'archive ouverte pluridisciplinaire HAL, est destinée au dépôt et à la diffusion de documents scientifiques de niveau recherche, publiés ou non, émanant des établissements d'enseignement et de recherche français ou étrangers, des laboratoires publics ou privés.

\section{(c)(1)}

Distributed under a Creative Commons Attribution| 4.0 International License 


\section{OPEN BIOLOGY}

royalsocietypublishing.org/journal/rsob

Received: 2 June 2021

Accepted: 5 0ctober 2021

\section{Subject Area:}

microbiology

\section{Keywords:}

Salmonella, poultry, host-pathogen

interaction, invasion, gall bladder

\section{Author for correspondence:}

I. Virlogeux-Payant

e-mail: isabelle.virlogeux-payant@inrae.fr

†Present address: Lycée GrandmontLaboratoire de Biotechnologies, 37204 Tours, France.

Electronic supplementary material is available online at https://doi.org/10.6084/m9.figshare. c.5684666.

\section{A large panel of chicken cells are invaded in vivo by Salmonella Typhimurium even when depleted of all known invasion factors}

S. M. Roche, S. Holbert, Y. Le Vern, C. Rossignol, A. Rossignol ${ }^{\dagger}$, P. Velge and I. Virlogeux-Payant ${ }^{\dagger}$

INRAE, Université de Tours, ISP, 37380 Nouzilly, France

SH, 0000-0001-7655-3144; PV, 0000-0002-8201-0194; IV-P, 0000-0003-4149-0168

Poultry are the main source of human infection by Salmonella. As infected poultry are asymptomatic, identifying infected poultry farms is difficult, thus controlling animal infections is of primary importance. As cell tropism is known to govern disease, our aim was therefore to identify infected hostcell types in the organs of chicks known to be involved in Salmonella infection and investigate the role of the three known invasion factors in this process (T3SS-1, Rck and PagN). Chicks were inoculated with wild-type or isogenic fluorescent Salmonella Typhimurium mutants via the intracoelomic route. Our results show that liver, spleen, gall bladder and aortic vessels could be foci of infection, and that phagocytic and non-phagocytic cells, including immune, epithelial and endothelial cells, are invaded in vivo in each organ. Moreover, a mutant defective for the T3SS-1, Rck and PagN remained able to colonize organs like the wild-type strain and invaded non-phagocytic cells in each organ studied. As the infection of the gall bladder had not previously been described in chicks, invasion of gall bladder cells was confirmed by immunohistochemistry and infection was shown to last several weeks after inoculation. Altogether, for the first time these findings provide insights into cell tropism of Salmonella in relevant organs involved in Salmonella infection in chicks and also demonstrate that the known invasion factors are not required for entry into these cell types.

\section{Background}

Salmonella spp. are among the most important foodborne pathogens. From a public health perspective, according to the World Health Organization, Salmonella spp. are among the 31 diarrhoeal and/or invasive agents (viruses, bacteria, protozoa, helminths and chemicals) displaying the highest capability of triggering intestinal or systemic diseases in humans. Most cases of salmonellosis are mild, but sometimes the disease is life-threatening and salmonellosis is the third leading cause of death among food-transmitted diseases [1].

The two most commonly reported non-typhoïdal serovars Salmonella enterica subsp. enterica serovar Enteritidis and Salmonella enterica subsp. enterica serovar Typhimurium (including its monophasic variant) account for almost $80 \%$ of human cases occurring in the EU [2]. Depending on host factors and serovars, Salmonella can induce a wide range of diseases ranging from systemic to asymptomatic infections and gastroenteritis [3]. In humans, localized infections can be followed by bacteraemia in 3-10\% of cases [4].

Animals are the primary source of these pathogens and humans become infected mainly by ingesting contaminated food. Poultry meat and eggs are the main source of human Salmonella contamination. In 2010, Knight-Jones 
et al. [5] reported that poultry was implicated as the source of outbreak in $10.4 \%$ of the total cases worldwide. Since 2018, Salmonella-positive single samples have represented the highest prevalence following official control investigations [2]. The detection and eradication of Salmonella in poultry is difficult because Salmonella infection mostly induces an asymptomatic infection, accompanied by high faecal excretion, which is a source of transmission [6]. Consequently, contaminated poultry flocks have to be eradicated and all derived products destroyed, resulting in high economic losses. It is therefore particularly important to control animal infection not only to avoid economic consequences but also to prevent the negative impacts on human health.

To establish infection in their hosts, Salmonella have to interact with several phagocytic and non-phagocytic eukaryotic cells. Invasion of these cells is considered as one of the key steps in Salmonella pathogenesis. The best-known invasion process requires the type III secretion system-1 (T3SS-1) encoded by Salmonella pathogenicity island 1 (SPI-1). The T3SS- 1 is a needle-like structure, which injects bacterial effector proteins directly into the host cytosol to manipulate the cell cytoskeleton, allowing bacterial internalization into non-phagocytic cells [7]. Two other in vitro entry pathways, involving the Rck and PagN invasins, have also been described in Salmonella [8-10]. Contrary to the T3SS-1, each invasin interacts with a eukaryotic receptor, EGFR and the heparinated proteoglycan for Rck and PagN, respectively [11,12]. In vivo, several studies particularly in mice have reported the key role of the T3SS-1 for Salmonella to cross the intestinal barrier $[13,14]$. Nevertheless, infections in the absence of T3SS-1 in mice, chicks and calves have also been described in several papers in which a mutant defective for the T3SS-1 was shown to colonize its host as efficiently as its wild-type parent [15-20]. This has also been observed in humans in whom food-borne disease outbreaks have been described with Salmonella Senftenberg isolates which lack segments of SPI-1 [21]. Similarly, a study performed by Suez et al. [22] comparing the pathogenicity of different non-typhoïdal strains concluded that Salmonella virulence factors, including multiple T3SS effectors, were absent from several bacteraemia isolates suggesting they are not required for invasive infection. Less is known about the role of the Rck and PagN invasins in vivo, but pagN (formerly iviVI-A) and $r c k$ mutants are both less competitive than their wild-type parent in mice [23-25]. However, apart from these roles identified at the organ level, very little is known about the cells targeted by these invasion factors and this is particularly the case in farm animals.

This topic is crucial because cell and tissue tropism governs disease in many models [26,27]. Moreover, some studies have shown that depending on the entry mechanism both bacterial behaviour and host response are different [28]. It is therefore important to identify the host cells targeted by Salmonella and the different entry routes used by this pathogen to invade the different host cells. In order to improve understanding of how Salmonella infect chicks, our aim was to identify the cells in four different organs known to be involved in Salmonella infection of this species that could be targeted in vivo by this pathogen when expressing or not the known invasion factors. For this purpose, we used a fluorescent $S$. Typhimurium wildtype strain and its fluorescent mutant derivatives deleted of either the T3SS-1 alone or of the three known invasion factors (T3SS-1, Rck and PagN) to infect chicks in the coelomic cavity. The use of the mutants aimed to investigate the impact of these factors on the invasion of the cell types infected by Salmonella. Identification of phagocytic and non-phagocytic cells and their invasion by the different bacteria were monitored using flow cytometric analyses and confocal microscopy.

\section{Methods}

\section{1. pFPV-TurboFP650 plasmid construction}

Gene encoding TurboFP650 was amplified from the plasmid pTurboFP650-N (Evrogen, Moscow, Russia) with primers TurboFP650-XbaI 5'-TGCTCTTAGATTTAAGAAGG AGATATAGATATGGGAGAGGATAGCGAGCTG-3' and TurboFP650-SphI 5'-CATGCATGCTTAGCTGTGCCCCAGTTTGC TAGG-3'. Then, the PCR product and the pFPV25.1 plasmid [29] were restricted by XbaI and SphI restriction enzymes, ligated and transformed into Escherichia coli MC1061 [30]. pFPVTurboFP650 recombinant plasmids were selected on Trypticase Soya Agar (TSA-BD Difco, Franklin Lakes, USA) containing $100 \mu \mathrm{g} \mathrm{ml}^{-1}$ of carbenicillin (Sigma-Aldrich, Saint-Quentin Fallavier, France) and clones which showed a purple colour were selected for restriction analysis. Clones with good restriction profiles were then sequenced to confirm the absence of mutations in the TurboFP650 coding sequence.

\subsection{Strains used and inocula preparation}

The pFPV-TurboFP650 plasmid was introduced in S. Typhimurium 14028 wild-type (WT), the $\Delta$ invA::kan mutant ( $\triangle$ invA; T3SS-1 defective) or the $\Delta i n v A:: k a n$ pagN::cm $\Delta r c k$ mutant $(3 \Delta)$ [31].

To prepare the inocula, the strains were cultured in Trypticase Soya Broth (TSB - BioMérieux) supplemented with carbenicillin $100 \mu \mathrm{g} \mathrm{ml}{ }^{-1}$ for $24 \mathrm{~h}$ at $37^{\circ} \mathrm{C}$ with shaking. The cultures were centrifuged at $4500 \mathrm{~g}$ for $20 \mathrm{~min}$ at $20^{\circ} \mathrm{C}$ and the pellets were suspended in phosphate buffered saline (PBS) containing 50\% glycerol. The bacterial suspensions were then aliquoted, frozen and stored at $-80^{\circ} \mathrm{C}$. The frozen aliquots from the same initial inoculum were used throughout the experiments.

\subsection{Experimental infection}

Five-day-old PA12 White Leghorn chicks, provided by the Experimental Platform for Infectious Disease (UE 1277INRAE), were inoculated in the coelomic cavity with $0.2 \mathrm{ml}$ of bacterial suspension. On the day of inoculation, a frozen aliquot of the inoculum was thawed. Bacteria concentrations were standardized turbidimetrically and diluted to a concentration of $6 \times$ $10^{7} \mathrm{CFU}$ per $0.2 \mathrm{ml}$ in PBS. Chicks were maintained in medium isolator systems $\left(0.83 \mathrm{~m}^{2}\right)$ with controlled environmental conditions (feed, water, temperature, air humidity and lighting scheme) for 2 days before sacrifice by decapitation and bleeding. To follow the persistence in the gall bladder, the inoculation dose was $3 \times 10^{7} \mathrm{CFU}$ per chick, in order to reduce the mortality of chicks observed with the higher dose. The kinetics of organ colonization was monitored each week over a period of 36 days.

\subsection{Enumeration of bacterial load in infected organs}

On the day of sacrifice, control animals of the same age (i.e. not inoculated) were provided by the Experimental Platform for Infectious Disease. Spleens, livers, gall bladders and the 
aortic vessels were collected aseptically from each animal for quantification of bacterial load.

To determine the bacterial load, organs were homogenized in TSB and serial 10-fold dilutions were plated on TSA or Salmonella-Shigella medium supplemented with carbenicillin $100 \mu \mathrm{g} \mathrm{ml}^{-1}$. The colonies per plate were counted after incubation for $24 \mathrm{~h}$ at $37^{\circ} \mathrm{C}$. Counts were expressed as log (CFU) per gram of organ.

\subsection{Preparation of cells for flow cytometry}

For the flow cytometric analyses, organ-specific samples were obtained by pooling the spleens, livers, aortic vessels and gall bladders of the different chicks in Hanks's buffered saline solution (HBSS) without $\mathrm{Ca}^{2+}$ and $\mathrm{Mg}^{2+}$ in the dark at $4^{\circ} \mathrm{C}$ in order to be able to analyse at least 200000 cells for each organ. Independent infections were repeated at least three times. Gall bladders and aortic vessels were cut into small pieces and samples put in collagenase A $(0.3 \%$ - Sigma $)$ - dispase I ( $1 \mathrm{U} \mathrm{ml}^{-1}$ —Sigma)-HBSS for $30 \mathrm{~min}$ at $37^{\circ} \mathrm{C}$. The whole purification process was performed at $4^{\circ} \mathrm{C}$. All organs were then homogenized in HBSS using syringe plungers and filtered through $40 \mu \mathrm{m}$-mesh cell strainers (BD Falcon, Tewksbury, USA), before being transferred into a $50 \mathrm{ml}$ centrifuge. After centrifugation at $1000 \mathrm{~g}$ for $15 \mathrm{~min}$, cells were washed, resuspended in HBSS at approximatively $5.10^{6}-1 \cdot 10^{7}$ cells $\mathrm{ml}^{-1}$ and maintained in the dark at $4^{\circ} \mathrm{C}$.

\subsection{Flow cytometric analyses}

Cells were characterized according to the antibodies available in poultry (electronic supplementary material, table S2). Mouse Anti-Chicken antibody, clone KUL01 specifically recognizes chicken monocytes, macrophages and interdigitating cells [32]. Anti-CT3 antibody targets the avian homologue of the CD3-antigen, a common antigen used to identify $\mathrm{T}$ lymphocytes [33]. Clone AV20 antibody recognizes the antigen Bu-1, a chicken B-cell marker, commonly used to identify B lymphocytes [34]. Mouse anti-chicken CD41/ 61 clone 11C3 recognizes chicken integrin CD41/61 that is expressed on chicken thrombocytes and cells of the thrombocyte lineage [35]. Mouse anti L-CAM antibody recognizes an $81 \mathrm{kDa}$ N-terminal tryptic fragment of L-CAM, an epithelial cell marker, from embryonic chicken liver plasma membranes [36] and finally VE-cadherin is an intercellular junction marker of endothelial cells. This is a synthetic peptide corresponding to human VE-cadherin amino acids from position 750 to the C-terminus conjugated to keyhole limpet haemocyanin. Rabbit polyclonal antibody anti-VE-cadherin clone reacts with mouse, chicken and human VE-cadherin.

Anti-Bu-1 and the anti-CD3, that allow B and T lymphocytes to be identified, were FITC conjugated. Antibodies allowing monocytes-macrophages, thrombocytes, epithelial and endothelial cells to be identified, required Alexa Fluor 488 conjugated anti-secondary anti-mouse or anti-rabbit antibodies. The endothelial cell samples were pre-treated with $20 \%$ horse serum. The primary antibodies were incubated with cells for $90 \mathrm{~min}$ at $4^{\circ} \mathrm{C}$ in the dark and then rinsed in HBSS. When necessary, secondary antibodies were added for $90 \mathrm{~min}$ at $4^{\circ} \mathrm{C}$ in the dark, and then rinsed. Appropriate isotype-control antibodies (electronic supplementary material, table S2) were used to determine the levels of unspecific staining in all the experiments. Parallel samples were stained with a
Fixable Viability Dye Cell Staining eFluor 450 (eBioscience, San Diego, USA) to determine the settings for a live cell gate based on light scatter properties. All samples were then filtered through $60 \mu \mathrm{m}$ nylon Blutex immediately before flow cytometric analyses were performed using a BD LSR Fortessa X-20 (BD Biosciences, San Jose, CA, USA). BD FACSDiva software (v. 8.0.2, RRID:SCR_001456) was used to analyse the cytometric data. Infected and control samples were manipulated under the same conditions.

\subsection{Identification and relative quantification of infected and non-infected cells by flow cytometry}

For each sample, dot plots were analysed. The intensity of green fluorescence (FITC or Alexa Fluor 488) on the vertical axis was plotted against the intensity of red fluorescence (TurboFP650) on the horizontal axis. Labelled infected cells thus emitted both green and red fluorescence. They were revealed as dots in the upper right-hand part of the graph. For each experiment in each organ, a gate was determined removing inappropriate labelling-debris based on morphological criteria. Regions were set according to uninfected control samples and isotype-control staining. In order to have quantitative results, 200000 events were analysed for each sample for all staining. Examples are provided for some cell-type/ organ labelling: for monocytes-macrophages (electronic supplementary material, figure S1) and thrombocytes (electronic supplementary material, figure S2) in the gall bladder, B lymphocytes (electronic supplementary material, figure S3) and T lymphocytes (electronic supplementary material, figure S4) in the spleen, epithelial cells in the liver (electronic supplementary material, figure S5), and endothelial cells in the aortic vessels (electronic supplementary material, figure S6). Quantification of the percentage of positively labelled cells was then calculated by subtracting the number of cells in the control areas from those in the positive labelled areas. The positive labelling areas of $\mathrm{B}$ and $\mathrm{T}$ lymphocytes cells were established using a control mouse IgG1-FITC conjugate, whereas the positive labelling areas of monocytes-macrophages, thrombocytes and epithelial cells were determined with a control mouse IgG1-Alexa Fluor 488 conjugate. For the labelling of the endothelial cells, we used rabbit IgG, followed by a secondary antibody, an anti-IgG-Alexa Fluor 488 conjugate. The total percentages of infected cells which were positively labelled or unlabelled were also determined. All negative responses were scored at $0.001 \%$ to account for the threshold and to allow for a logarithmic representation of the results. The medians are represented by a red dash.

\subsection{Purification of the infected cells and confocal laser-scanning analysis}

Cells were sorted using a high-speed cell sorter, MoFlo Astrios $^{\mathrm{EQ}}$ (Beckman Coulter Inc, Brea, CA, USA) equipped with four lasers: violet $(405 \mathrm{~nm})$, blue $(488 \mathrm{~nm})$, yellow-green $(561 \mathrm{~nm})$ and red $(640 \mathrm{~nm})$ and placed under a class II biological safety cabinet. We used a $90 \mu \mathrm{m}$ nozzle and selected a sheath pressure of 40 psi. Sorted cells were collected in $1.5 \mathrm{ml}$ Eppendorf tubes containing $350 \mu \mathrm{l}$ of HBSS medium supplemented with $10 \%$ fetal calf serum to limit cell stress.

After cell sorting, samples were deposited on glass coverslips and centrifuged with a cytospin at 200 r.p.m. for $10 \mathrm{~min}$. 
Cells were then fixed in formaldehyde $4 \%$ for $10 \mathrm{~min}$. Nucleus staining was performed with DAPI $1 \mu \mathrm{g} \mathrm{ml}^{-1}$ for 1 min and coverslips were mounted on slides with fluorescent mounting medium (Dako). Cells were observed under a SP8 confocal laser-scanning microscope equipped with an HCP PL APO 100×/1.44 Oil CORR CS immersion objective (Leica). Z-stacks were re-sliced horizontally and vertically to obtain the projections of perpendicular views from three-dimensional images, providing a view of all bacteria in the cells, using Las AF lite 2.6.3 build 8173 software (Leica application Suite X, RRID:SCR_013673).

\subsection{Immuno-histochemistry (IHC)}

Chick gall bladders were fixed in $4 \%$ buffered paraformaldehyde (Electron Microscopy Sciences, Hatfield, England) at $4^{\circ} \mathrm{C}$ for $24 \mathrm{~h}$. They were then processed by routine methods, they were paraffin (Surgipaht Paraplast Plus Leica, Richmond, USA) embedded, cut in sections (thickness, $5 \mu \mathrm{m}$ ), and stained for IHC with HRP detection. All samples were incubated at room temperature. The primary antibody was an anti-Salmonella lipopolysaccharide marker: rabbit antiSalmonella O:4,5 (1/100-Diagnostics Pasteur, Marne-laCoquette, France). The tissue sections were dewaxed in Histosol (Shandon, Cergy Pontoise, France), rehydrated in a decreasing series of ethanol, rinsed and rehydrated in tap water. Sections were treated with heat-induced epitope retrieval, $10 \mathrm{mM}$ sodium citrate buffer, $\mathrm{pH} 6,121^{\circ} \mathrm{C}$, for $15 \mathrm{~min}$. The tissues were then rinsed in tap water. The endogen peroxidase was blocked in $1 \%$ hydrogen peroxide and methanol for $30 \mathrm{~min}$. Preparations were rinsed in PBS with $1 \%$ skimmed milk and 0.05\% Tween 20 (PBSTM), blocked in $20 \%$ goat serum $-30 \%$ fetal calf serum-PBS for $20 \mathrm{~min}$. They were then incubated with a primary antibody for $60 \mathrm{~min}$ and rinsed in PBSTM, followed by N-Histofine rabbit, HRP (Nichirei Biosciences, Tokyo, Japan) for $30 \mathrm{~min}$. At the end, samples were rinsed in PBSTM, incubated with chromogen (diaminobenzidine, liquid DAB) (DAB Quanto, Lab Vision Corporation, Fremont, USA) for $5 \mathrm{~min}$, counterstained with haematoxylin of Harris (Merck, KGaA, Darmstadt, Germany), rinsed in tap water, dehydrated in successive ethanol baths $\left(50^{\circ}, 70^{\circ}, 90^{\circ}\right.$ and absolute, each for $2 \mathrm{~min}$ ), cleared in histosol and mounted on coverslips with Eukitt (ORSAtec, Bobingen, Germany).

Tissues were examined and photographed with a light microscope Eclipse 80i, Nikon with DXM 1200C digital camera (Nikon Instruments, Europe, Amsterdam, The Netherlands) and NIS-Elements D Microscope Imaging Software (NIS-Elements, RRID:SCR_014329).

\subsection{Statistical analyses}

A Kruskal-Wallis test was conducted to examine the differences in the levels of organ colonization, followed by a Dunn's multiple comparisons test (GraphPad Prism v. 6.07 for Windows, GraphPad, www.graphpad.com, RRID: SCR_002798). Significance was ${ }^{*} p<0.05$ and ${ }^{* *} p<0.01$.

For the flow cytometric analyses, asymptotic two-sample Fisher-Pitman permutation tests (one-way test) were performed with R software, package Rcmdr v. 2.5.3 (R Project for Statistical Computing, RRID:SCR_001905). Significance was ${ }^{*} p<0.05$ (http://www.r-project.org, http://socserv. socsci.mcmaster.ca/jfox/Misc/Rcmdr/).

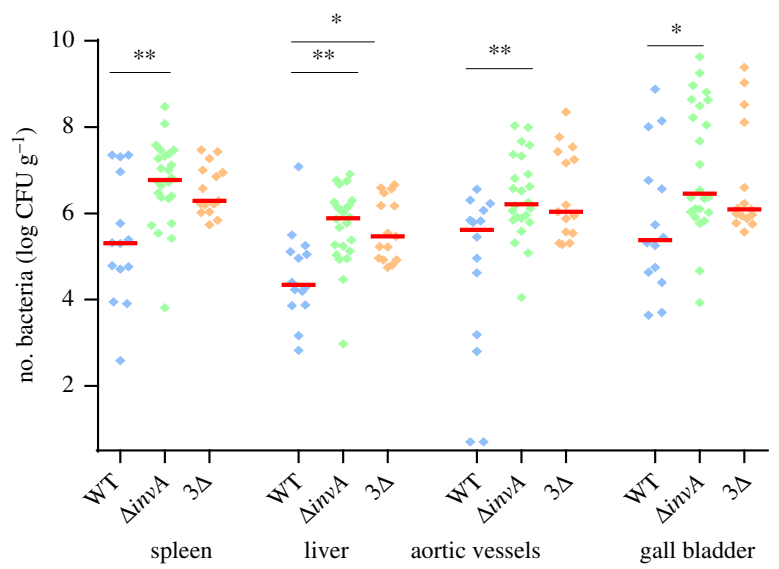

Figure 1. Level of different $S$. Typhimurium strains in organs of chicks after intracoelomic inoculation. Five-day-old chicks were inoculated in the coelomic cavity with around $6 \times 10^{7}$ CFU per chick with S. Typhimurium 14028 turboFP650 wild-type strain (WT; blue diamond), $\Delta$ invA::kan mutant strain ( $\triangle$ invA; T3SS-1 defective; green diamond) or the $\triangle i n v A:: k a n$ $\triangle p a g N:: c m$ $\Delta r c k$ mutant strain (3 $\Delta$; T3SS-1, Rck, PagN defective; yellow diamond). Two days post infection, spleens, livers, aortic vessels and gall bladders were removed aseptically from each animal for quantification of bacterial load. Results are expressed as number of bacteria per gram of organ (log (FU per gram of organ). The medians are represented by a red dash. A Kruskal-Wallis test was conducted, followed by Dunn's multiple comparisons test (GraphPad Software). Significance was ${ }^{*} p<0.05$ and ${ }^{* *} p<0.01$.

\section{Results and discussion}

\subsection{Mutant strains defective for the T3SS-1 or the three known invasion factors inoculated by the intracoelomic route colonize chicks more effectively than their wild-type parent strain}

Previous work has shown that a $\triangle i n v A$ mutant strain (T3SS-1 defective strain) and a strain deleted for the three known invasion factors $(3 \Delta)$ remained invasive for several eukaryotic cell lines compared to the wild-type strain [31]. To determine the ability of our wild-type mutant strains to invade several host cells in vivo, we infected chicks in the coelomic cavity (also abusively referred as intraperitoneal route) in order to have a sufficient number of Salmonella colonizing the targeted organs to allow infected cells to be identified in these organs. The first step was to evaluate the ability of these different strains to colonize vessels and different organs of chicks (i.e. the spleen, liver and gall bladder; figure 1). The vessels were chosen because Salmonella is able to spread through the body via the blood, and the spleen and liver as they are colonized by Salmonella in chicks $[37,38]$. Finally, we decided to study the gall bladder as well because Gonzalez-Excobedo \& Gunn [39] demonstrated that the gallbladder epithelium contributed to establishing and maintaining chronic carriage in mice. To ensure that the levels of bacteria were not related to the presence of Salmonella in the blood, all chicks were bled.

The first observation is that all strains were able to infect all the organs and vessels. For some animals, the infection rate even reached $8 \log \mathrm{CFU} \mathrm{g}^{-1}$, particularly for the gall bladder. Moreover, all organ colonization levels were higher after inoculation with the $\triangle i n v A$ strain than with the wildtype strain $(29,35,3.9$ and 12 times greater in the spleen, liver, aortic vessels and gall bladder, respectively). All these 
differences were statistically significant. While the $3 \Delta$ strain also colonized these organs and vessels more effectively than the wild-type strain $(9.5,13,2.6$ and 5.1 times greater in the spleen, liver, aortic vessels and gall bladder, respectively), a statistically significant difference was only identified in the liver. No significant statistical difference could be observed between the two mutants, beside the fact that the $\log \mathrm{CFU}$ of bacteria $\mathrm{g}^{-1}$ for the $3 \Delta$ strain was always inferior to that of organs for the $\triangle i n v A$ strain. The levels of CFU recovered in the gall bladder and the aortic vessels should be highlighted, as they have rarely been studied in the past. These results demonstrate that all the organs and vessels tested were colonized by wild-type $S$. Typhimurium and that the two mutant strains $(\triangle i n v A$ or $3 \Delta$ ) colonized these organs of chicks after intracoelomic inoculation at least at the same level as the wild-type strain.

This latter result could be attributed to the route of inoculation. Indeed, Salmonella injected into the coelomic cavity easily reach systemic sites such as the spleen and the liver. They could also reach the gall bladder through the vasculature or the hepatic duct [40]. In vivo studies have demonstrated that the T3SS-1 is primarily associated with the early stage of infection during which it translocates T3SS1 effectors across the host intestinal epithelial cell membrane and stimulates intestinal inflammation [13,14,41-43], thus playing an important role in Salmonella colonization after animals are inoculated orally. Our results show that, in chicken, the colonization of systemic organs can be independent of this type III secretion system as no difference in colonization between a T3SS-1 mutant and its wild-type parent was observed as described after intraperitoneal or intravenous inoculation of mice. In our case, one hypothesis that could explain the higher colonization of the mutant strains compared to the wild-type strain is that after intracoelomic inoculation the absence of the T3SS-1 could induce a lower immune system alert, in particular a lower inflammatory response and consequently less bacteria being killed. Indeed, SPI-1 genes are involved in the regulation of the host immune response, for example the host inflammatory response [44], immune cell recruitment [45] and apoptosis $[46,47]$. Moreover, we already know that a SPI-1 mutant and also a phoP mutant, not expressing PagN like our $3 \Delta$ mutant, did not stimulate an inflammatory response in chick caeca [48].

Cytometric analyses and microscopy were then performed in order to determine whether Salmonella was within the cells of the different organs and vessels and to identify the cell-types infected. The infectious dose of $6 \times 10^{7} \mathrm{CFU}$ per chick used for the previous in vivo experiment, represented a good compromise between the infectious dose and the period of slaughter (2 days), to enable enough intracellular bacteria to be detected for flow cytometry analyses. The animals were bled to reduce the number of red blood cells and allow better detection of organ cells. The concentration of $S$. Typhimurium-TurboFP650-wild-type (STM-Turbo FP650-WT) strain was checked in the blood of six animals. An average of 1.95 $\pm 1.09 \log \mathrm{CFU} \mathrm{ml} \mathrm{m}^{-1}$ was found.

\subsection{STM-Turbo FP650-WT and its mutant strains}

\section{were within the cells and did not only adhere to the cells}

As our aim was to identify cells infected by Salmonella, we first assessed whether our protocol allowed us to identify intracellular bacteria or not. Indeed, flow cytometry is useful for quantitative analyses but it does not enable bacteria to be localized as either adherent or intracellular. According to our protocol, it was highly unlikely that Salmonella would only be present extracellularly due to the methods used to purify and mechanically separate the cells, including filtrations and washings and, for some organs enzymatic cleavage with two different enzymes (collagenase and dispase) was also performed for cell purification. Theoretically, after all these treatments related to organ dissociation, only a few bacteria would remain adhered, suggesting that the large majority were intracellular. However, in order to confirm this, cell sorting based on the labelling of the cells and confocal analyses were carried out for each cell type of each organ. For flow cytometry, regions corresponding to infected cells were identified with the PE-cy5 canal and were set according to uninfected control samples. The Alexa fluor 488 canal was used to identify the cell types according to the isotype-control staining. One example for each cell type is given in electronic supplementary material, figures S1-S6. Double-labelled cells were sorted using flow cytometry and observed with confocal microscopy. A Z-stack was re-sliced horizontally and vertically to obtain the projections of perpendicular views, confirming the intracellular presence of bacteria. This allowed us to observe intracellular Salmonella expressing red tag, in green labelled cells for all the cells considered. These results confirm the intracellular localization of the different strains and thus validate our protocol designed to identify and quantify the cell types infected by Salmonella in selected chick organs. Moreover, they show that $S$. Typhimurium can invade all the cell types studied in this paper (i.e. monocytes-macrophages, B and T lymphocytes, thrombocytes, epithelial and endothelial cells of chicks). Currently, only a few papers have described the cells infected by Salmonella in vivo and most of these papers are in mouse models. In these articles, Salmonella were found mainly in macrophages and neutrophils from the liver and spleen of mice, but infected B and T lymphocytes were also identified [49-52].

A more detailed analysis of the confocal images allowed us to observe that in most cases infected cells, whatever the cell type, only harboured one to five bacteria per cell (figure 2), but in a few more bacteria were visualized. This result is consistent with results obtained in the literature on Salmonella infected macrophages in vivo. Indeed, in many experiments in mice, the majority of liver or spleen infected phagocytes contained relatively few bacteria [49-51,53], but the presence of many bacteria per cell has also been reported $[50,53,54]$. Our results show that this heterogeneous number of bacteria per cell could be extended to non-phagocytic cells in chicks. However, in mice it seems that the number of bacteria per cell had a moderate impact on the infectious process as host cells that contain high numbers of bacteria have the same probability of undergoing lysis as cells containing only a few bacteria [55]. Both highly and weakly infected cells contribute significantly to the Salmonella infection process and not only macrophages [51].

\subsection{Analysis of the infected cell types in the spleen}

In the chicken spleen the distinction between red and white pulp is less marked than in mammals. Red pulp mainly contains erythrocytes, granulocytes, macrophages, scattered $\mathrm{T}$ lymphocytes and plasma cells. However, the architecture of 
(a)

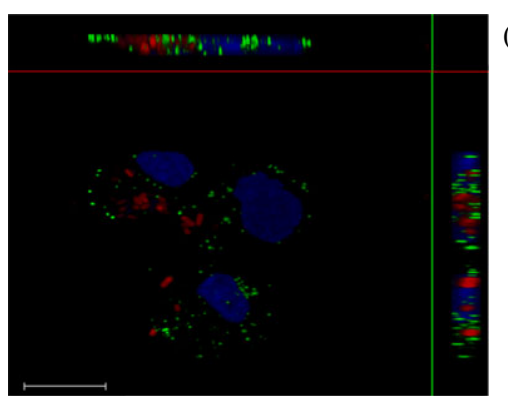

endothelial cells

(c)

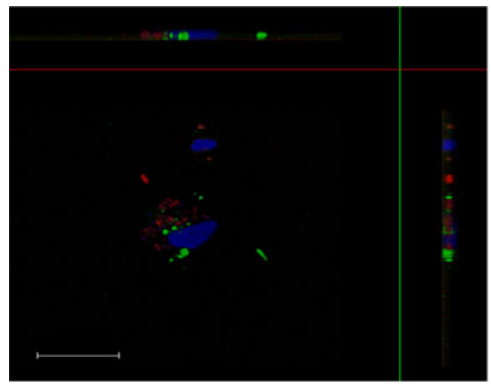

B lymphocytes

(e)

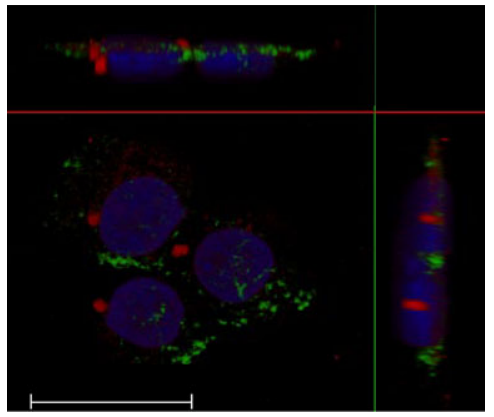

epithelial cells

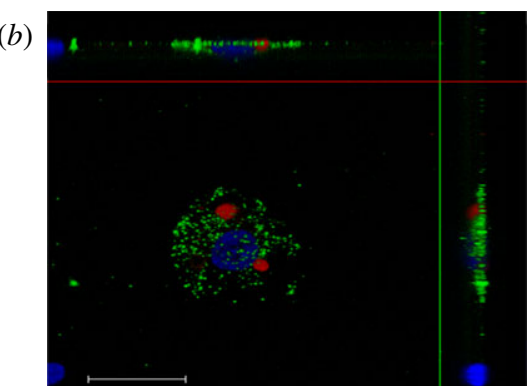

monocytes-macrophages

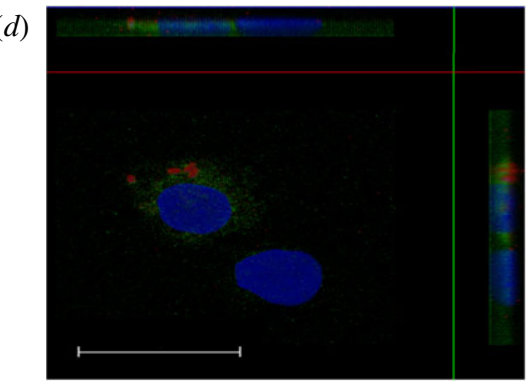

T lymphocytes

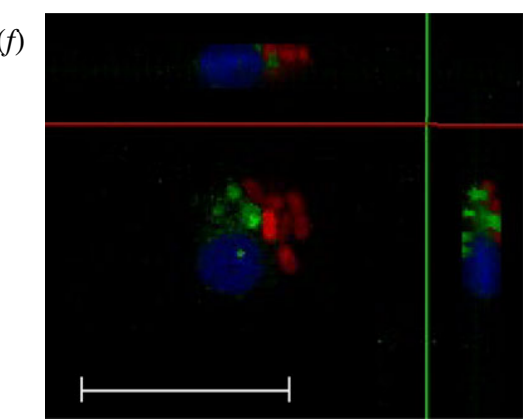

thrombocytes

Figure 2. Intracellular localization of Salmonella in cells purified from in vivo infected organs. Five-day-old chicks were inoculated in the coelomic cavity with around $6 \times 10^{7}$ CFU per chick with S. Typhimurium 14028 turboFP650 wild-type strain, $\Delta i n v A:: k a n$ mutant strain or the $\Delta i n v A:: k a n \Delta p a g N:: c m$ vrck mutant strain. Two days post infection, animals were sacrificed and the different organs removed. Cells were then isolated from organs, they were sorted using a high-speed cell sorter, MoFlo Astrios EQ and deposited on glass coverslips after cytospin at 200 r.p.m. for $10 \mathrm{~min}$. Next, cells were fixed in formaldehyde. Nucleus staining was performed with Dapi (blue). The bacteria are in red (turboFP650), whereas cells are identified in green due to FITC or Alexa Fluor 488 conjugated antibodies. Cells were observed under a SP8 confocal laser-scanning microscope equipped with a 100× oil immersion objective (Leica). Z-stacks were re-sliced horizontally and vertically to obtain the projections of perpendicular views from three-dimensional images, allowing a view of all bacteria in the cells, using Las AF lite 2.6 .3 build 8173 software (Leica). White dashes represent $20 \mu \mathrm{m}$. (a) Represents endothelial cells from the aortic vessels, infected with the $3 \Delta$ strain. Picture size $32.54 \times 38.45 \mu \mathrm{m}$. (b) Represents monocytes-macrophages from the liver, infected with the $\Delta i n v A$ strain. Picture size $116.25 \times 116.25 \mu \mathrm{m}$. (c) Represents B lymphocytes, infected with the wild-type strain. Picture size $58.13 \times 58.13 \mu \mathrm{m}$. (d) Represents T lymphocytes, infected with the wild-type strain. Picture size $39.88 \times 39.88 \mu \mathrm{m}$. (e) Represents epithelial cells in the gall bladder, infected with the $3 \Delta$ strain. Picture size $37.80 \times 37.80 \mu \mathrm{m}$. ( $f$ ) Represents thrombocytes in the aortic vessels, infected with the $3 \Delta$ strain. Picture size: $116.25 \times 116.25 \mu \mathrm{m}$.

avian white pulp differs considerably. Three morphologically distinct areas constitute the spleen. The first consists of peri-arteriolar lymphocyte sheaths, mainly containing $\mathrm{T}$ lymphocytes that surround arterioles, which have visible muscular layers. The second involves peri-ellipsoid lymphocyte sheaths (PELS) surrounding capillaries, lacking muscular tissue and lined by cuboidal endothelium and reticulin fibres. The last consists of follicles with germinal centres, surrounded by a capsule of connective tissue. PELS and follicles mainly contain B lymphocytes [56].

In the spleen, the six antibodies used in our study allowed us to detect about $86 \%$ of the total cells. Epithelial cell labelling was not necessary, as these cells were not expected to be present. As expected, B lymphocytes (average of $8 \%$ ), T lymphocytes (average of 22\%) and endothelial cells (average of $30 \%$ ) were identified the most (figure $3 a$ ). Compared to the non-infected chicks, the percentage of labelled cells was similar in the groups of chicks inoculated with the wildtype bacteria, the single or triple mutant bacteria. The only statistical difference was observed for the percentage of thrombocytes between the uninfected chicks and the chicks infected with the wild-type strain ( $p=0.049$; electronic supplementary material, table S1). The slight decrease in the number of thrombocytes after infection with the wild-type strain, was similar to that observed with the two mutants, but the number of independent experiments was probably not sufficient to obtain a statistical difference between the uninfected group and the chicks inoculated with these Salmonella mutants. Similarly, the lower percentage of macrophages observed after infection with the $3 \Delta$ mutant strain was not significant. This could be explained either by the absence of cell recruitment in chicks or more probably to the fact that 
(b)
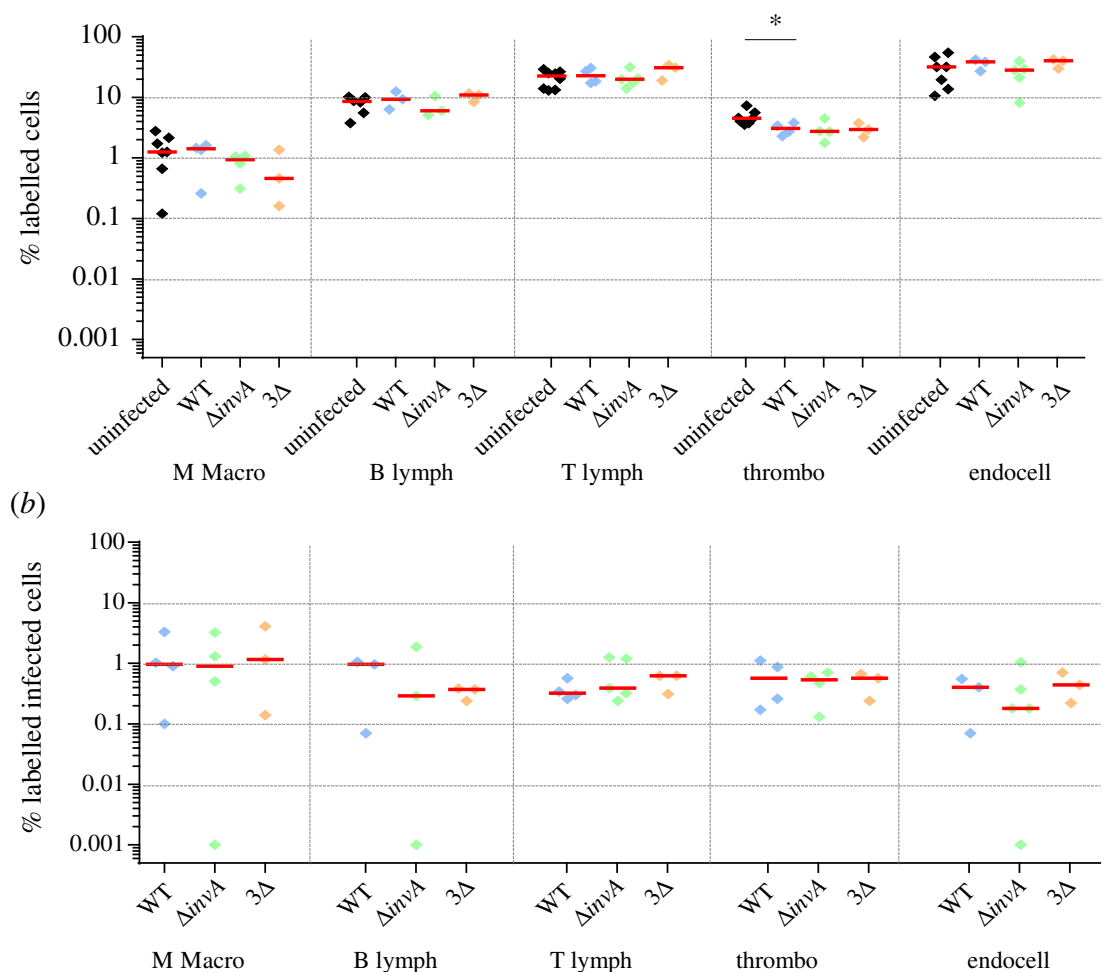

Figure 3. Percentage of identified and Salmonella infected cells in spleen 5-day-old chicks were inoculated in the coelomic cavity with around $6 \times 10^{7}$ CFU per chick with S. Typhimurium 14028 turboFP650 wild-type strain (WT; blue diamond), $\Delta i n v A:: k a n$ mutant strain ( $\Delta$ invA; T3SS-1 defective; green diamond) or the $\Delta$ invA::kan $\Delta$ pagN:: $c m$ rck mutant strain (3$\Delta ;$; T3SS-1, Rck, PagN defective; yellow diamond). Two days post infection, animals were sacrificed and the different organs removed. Cells from uninfected animals of the same age were used as a control. After labelling with the corresponding antibodies, the percentages of macrophages-monocytes, B and T lymphocytes, thrombocytes and epithelial and endothelial cells were quantified by flow cytometry. The percentage of labelled cells $(a)$ and the percentage of labelled infected cells $(b)$ are represented. All negative responses were scored at $0.001 \%$. The medians are represented by a red dash. Asymptotic two-sample Fisher-Pitman permutation tests (one-way test) were performed (R software). Significance was ${ }^{*} p<0.05$.

the infected cells were identified only 2 days after bacterial inoculation. The infection rates observed for all the cells identified (lymphocytes, macrophages, thrombocytes and endothelial cells) were between $0.1 \%$ and $1 \%$. Monocytes and macrophages were proportionally the most infected cells (about five times more than the other cell types), but endothelial cells, and $\mathrm{B}$ and $\mathrm{T}$ lymphocyte cells were the most infected cells in the spleen as their absolute number was higher than that of monocytes-macrophages in this organ. No statistical differences were observed between the Salmonella strains tested (figure $3 b$ ). The fact that monocytes-macrophages were identified as being proportionally the most infected cells of the spleen was not surprising. In mice, it is commonly assumed that the systemic spread of Salmonella is contingent upon dissemination and survival within macrophages. Indeed, survival in macrophages is essential for virulence [57]. However, contrary to what was assumed, our work clearly demonstrated that other cell types, such as lymphocytes, thrombocytes and endothelial cells of sinusoidal capillaries, could also be infected by Salmonella in chicken spleen. As monocytes and macrophages are phagocytic cells, the fact that there was no difference in the percentage of monocyte-macrophage infected cells between the mutants and the wild-type strain was to be expected. By contrast, B and T lymphocytes, thrombocytes and endothelial cells are non-phagocytic cells and thus a difference in the percentage of cells infected by the different strains could have been expected. However, Geddes et al. [52] have also described the internalization of Salmonella independently of the T3SS-1 in splenic B and T cells of mice. Our work suggests that this observation could be extended to other non-phagocytic cells of other animal species.

\subsection{Analysis of the infected cell types in the liver}

The liver is divided into a right and a left lobe. Each lobe of the liver has approximately 100000 lobules separated from each other by interlobular septum. These lobules are formed by parenchymal cells (hepatocytes), which represent $80 \%$ of the total liver volume, and non-parenchymal cells localized in the sinusoidal wall. These sinusoidal walls are the vascular side of the hepatocytes and they are composed of endothelial cells and macrophages. These macrophages are star-shaped and confined to the liver. Called Kupffer cells, they phagocyte pathogens, cell debris and damaged red and white blood cells [58].

In the liver, the six antibodies used allowed us to detect about $76 \%$ of the cells and we detected as many epithelial cells (average of $31 \%$ ) as endothelial cells (average of 33\%) (figure $4 a$ ). As expected, these were the main cell types identified. Few monocytes-macrophages were identified. One hypothesis is that the KUL01 antibody poorly recognizes Kupffer cells [59]. Another explanation could be that their percentage compared to epithelial and endothelial cells is very low in the liver. There were also almost no $\mathrm{T}$ lymphocytes. In humans and mice, lymphocytes are present in small quantities at the level of the sinusoids and the space of Disse (perisinusoidal space) and histological investigation 


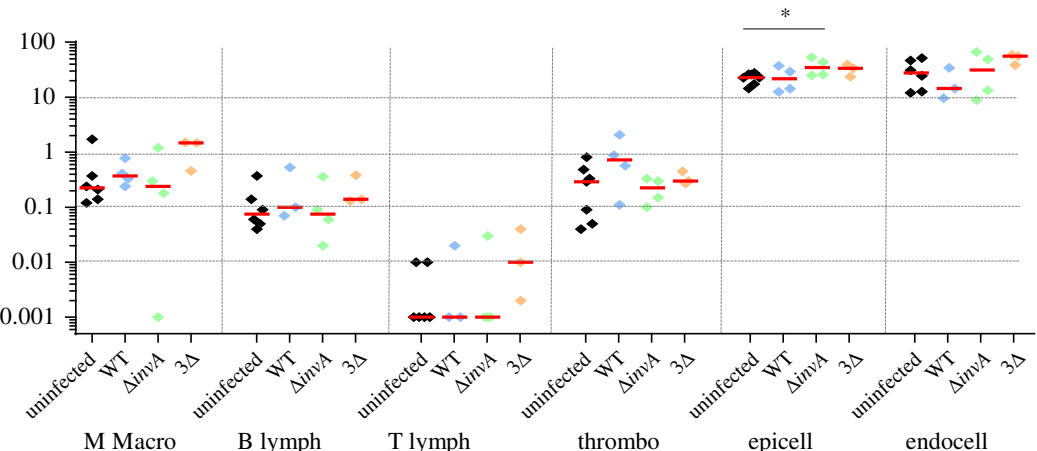

(b)

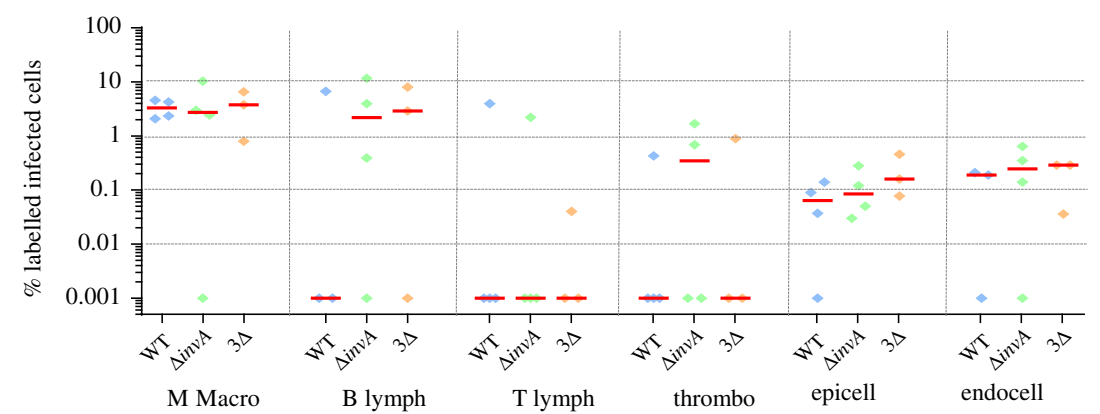

Figure 4. Percentage of identified and Salmonella infected cells in liver. Five-day-old chicks were inoculated in the coelomic cavity with around $6 \times 10^{7}$ CFU per chick with S. Typhimurium 14028 turboFP650 wild-type strain (WT; blue diamond), $\Delta$ invA::kan mutant strain ( $\Delta i n v A ;$ T3SS-1 defective; green diamond) or the $\Delta$ invA::kan $\Delta$ pagN:::cm $\Delta$ rck mutant strain (3 3 ; T3SS-1, Rck, PagN defective; yellow diamond). Two days post infection, animals were sacrificed and the different organs removed. Cells from uninfected animals of the same age were used as a control. After labelling with the corresponding antibodies, the percentages of macrophages-monocytes, B and T lymphocytes, thrombocytes and epithelial and endothelial cells were quantified through flow cytometry. The percentage of labelled cells $(a)$ and the percentage of labelled infected cells $(b)$ are represented. All negative responses were scored at $0.001 \%$. The medians are represented by a red dash. Asymptotic two-sample Fisher-Pitman permutation tests (one-way test) were performed (R software). Significance was ${ }^{*} p<0.05$.

does not suggest that there are many immunologically relevant cells present [60]. Liver-resident lymphocytes serve as sentinels and perform immunosurveillance in response to infection and non-infectious insults, and are involved in the maintenance of liver homeostasis [61]. Our low level of T lymphocytes in the liver is most probably related to the fact that our observations were made 2 days after the Salmonella inoculation and that our chicks were only 6 days old and therefore immunologically immature. For all cell types in the liver, the percentage of labelled cells was similar, whatever the infected or uninfected status of the animals. Only a statistical difference for the percentage of labelled epithelial cells between the uninfected chicks and those infected with the inv $A$ mutant was observed $(p=0.039$; electronic supplementary material, table S1). As in the spleen, we were able to observe similar levels of infected cells between chicks inoculated with the wild-type strain or with the two mutant strains deleted of the known entry factors. Compared to the spleen, there was a greater heterogeneity in the percentages of labelled infected cells (figure $4 b$ ). In particular, the percentages of infected monocytes-macrophages and B lymphocytes were around 3\%, while those of infected epithelial and endothelial cells were $0.10 \%$ and $0.24 \%$, respectively. Nevertheless, as the two latter cell types are more frequent in the liver than monocytes-macrophages and B lymphocytes (figure $4 a$ ), endothelial cells of sinusoidal capillaries and epithelial cells represent a large proportion of the infected cells in the liver. One of the roles of liver monocytes-macrophages is the phagocytosis of pathogens and thus it is not surprising that they were found infected, with no differences between any of the strains inoculated. By contrast, thrombocytes were very weakly infected here.
Overall, these results strengthen those observed in the spleen, showing that at least four different cell types (i.e. monocytes-macrophages, B lymphocytes, endothelial and epithelial cells) were infected by Salmonella in the liver of chicks.

\subsection{Analysis of the infected cell types in the aortic vessels}

The term 'aortic vessels' in our paper corresponds to the aortic arch and the brachiocephalic trunk. By contrast to mammals, two brachiocephalic trunks arise from the arch of the aorta and give rise to the common carotid and subclavian arteries in birds [62]. For this organ, only 55\% of the cells were identified through flow cytometric analysis. This low percentage of identification was mainly related to the presence of smooth muscle fibres in vessels for which no antibodies exist for the chicken. The adventitia, which is the outer layer of the arterial wall, is made up of connective tissue and elastic fibres. It contains capillary vessels vascularizing the arterial wall as well as nerve fibres of the sympathetic and parasympathetic autonomic system. According to the size of the arteries, the media, which is the middle layer of the arterial wall, is made up of collagen, elastin or smooth muscle fibres allowing vasoconstriction. The intima, the inner layer of the arterial wall separated from the media by the internal elastic limiter, consists of vascular endothelium (cell monolayer) resting on a layer of connective tissue [63].

The percentages of cells labelled in aortic vessels according to the chick group illustrated in figure $5 a$ varied more than for the previous two organs, probably due to the treatment of the aortic vessel with enzymes, which made extraction more 


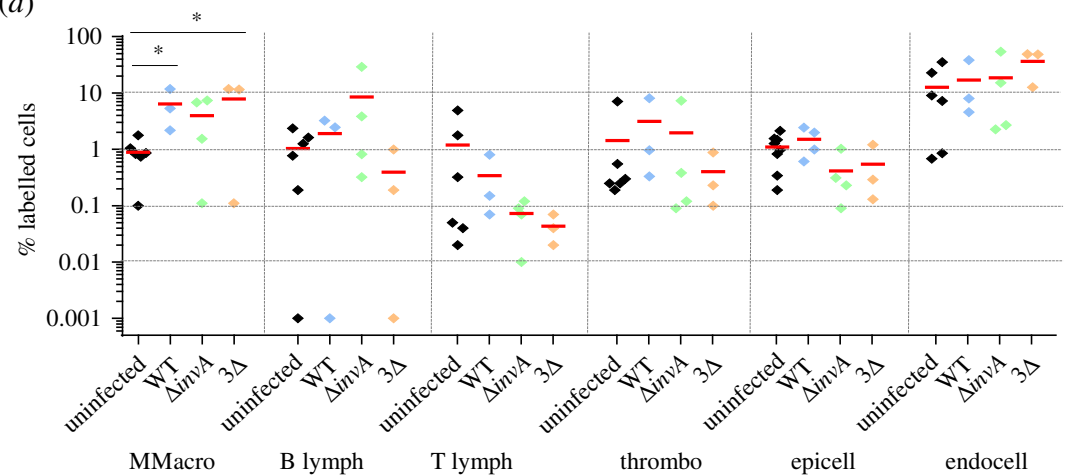

(b)

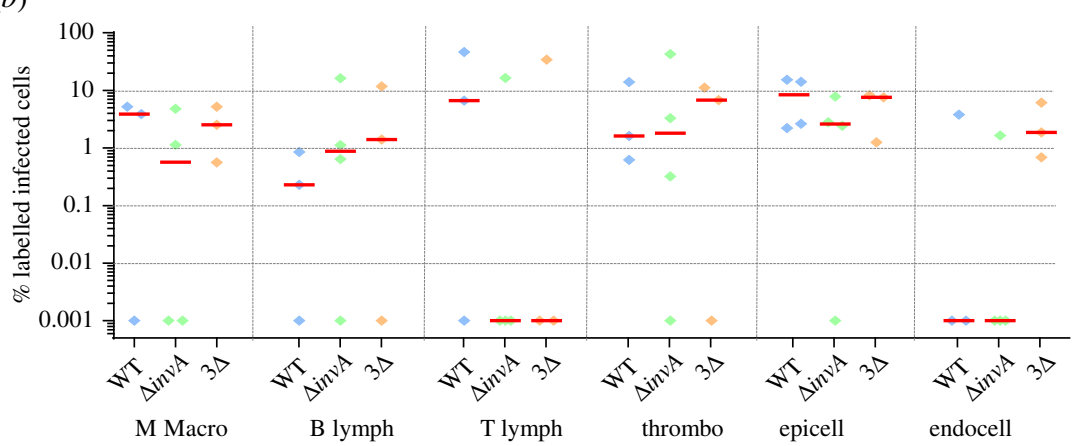

Figure 5. Percentage of identified and Salmonella infected cells in aortic vessels. Five-day-old chicks were inoculated in the coelomic cavity with around 6.107 CFU per chick with S. Typhimurium 14028 turboFP650 wild-type strain (WT; blue diamond), $\Delta$ invA::kan mutant strain ( $\Delta$ invA; T3SS-1 defective; green diamond) or the

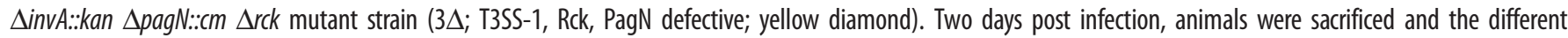
organs removed. Cells from uninfected animals of the same age were used as a control. After labelling with the corresponding antibodies, the percentages of macrophages-monocytes, B and T lymphocytes, thrombocytes and epithelial and endothelial cells were quantified by flow cytometry. The percentage of labelled cells $(a)$ and the percentage of labelled infected cells $(b)$ are represented. All negative responses were scored at $0.001 \%$. The medians are represented by a red dash. Asymptotic two-sample Fisher-Pitman permutation tests (one-way test) were performed (R software). Significance was ${ }^{*} p<0.05$.

difficult. Monocytes-macrophages and endothelial cells (of continuous capillaries) were the most representative type of cells labelled, but all cell types were identified (figure $5 a$ ). In this organ, we observed a difference between the percentages of monocytes-macrophages according to the uninfected or infected status of the animals. Contrary to the spleen and the liver, the percentage of labelled monocytes-macrophages showed statistically significant differences between the uninfected chicks and those infected with the wild-type strain, on the one hand ( $p=0.035$; electronic supplementary material, table S1), and those infected with the $3 \Delta$ mutant, on the other hand ( $p=$ 0.043; electronic supplementary material, table S1). Despite a high percentage of labelled endothelial cells, few if any were infected. By contrast, all the other cell types were infected and to a greater extent than in the spleen and liver (figure $5 b$ ). Indeed, compared to the spleen and liver, the median percentage of each infected cell type in the aortic vessels, except endothelial cells, varied from $1 \%$ to $10 \%$ versus $0.1-1 \%$ in the spleen or $0-3 \%$ in the liver. Surprisingly, in some chicks more than $10 \%$ of lymphocytes, thrombocytes and epithelial cells were infected.

These results clearly show that, like in the spleen and liver, numerous cell types are infected in vessels.

\subsection{Analysis of the infected cell types in the gall bladder}

The avian gall bladder is attached to the right liver lobe. Histologically, it is composed of three tunicae. The first, the tunica mucosa is mainly lined with non-ciliated simple columnar epithelium and consists of a layer of connective tissue with elastic and muscle fibres. The second, the tunica muscularis consists of smooth muscle fibres and abundant intervening connective tissue. The third, the tunica serosa, consists of coarse collagen fibre and elastic fibres. All epithelial cells are basally located and contain an oval nucleus. Bile is synthesized in the hepatocytes and secreted into bile canaliculi located on the lateral surfaces of adjoining liver cells [64]. Relatively little is known about biliary secretion in birds due to the complex anatomy in which bile enters the intestine via both hepato-enteric and cystico-enteric ducts. In ruminants, pigs and poultry, there is a relatively continuous secretion of bile into the intestine [58].

About $75 \%$ of cells were identified with the available antibodies. Numerous 'unidentified cells' would most probably correspond to fibroblasts. All the cell types studied were identified. The epithelial cells represented about $60 \%$ of the identified cells and the percentages of thrombocytes and monocytes-macrophages were between $1 \%$ and $10 \%$ (figure $6 a$ ). B and $\mathrm{T}$ lymphocytes were present to a lesser extent. As for the aortic vessels, the variability between animals was considerable, certainly due to the breakdown of organs with different enzymes, which made extraction less reproducible. As in the other organs (except for the percentages of monocytes-macrophages in the aortic vessels), there were no differences in the percentages of the labelled cells between uninfected and infected chicks. When comparing the inoculated chicks, only one statistically significant difference was observed regarding the percentage of $\mathrm{T}$ lymphocytes between the chicks inoculated with the single or the triple mutant $(p=0.041$; electronic supplementary 
(a)

(b)

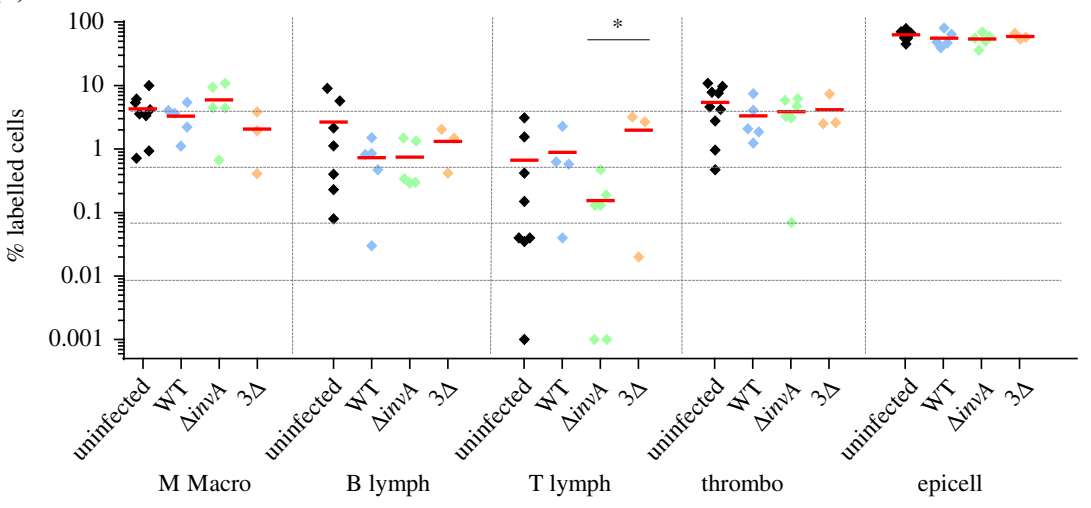

Figure 6. Percentage of identified and Salmonella infected cells in gall bladder. Five-day-old chicks were inoculated in the coelomic cavity with around $6.10^{7}$ CFU per chick with S. Typhimurium 14028 turboFP650 wild-type strain (WT; blue diamond), $\Delta$ invA::kan mutant strain ( $\Delta i n v A ;$ T3SS-1 defective; green diamond) or the

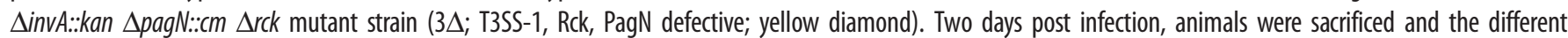
organs removed. Cells from uninfected animals of the same age were used as a control. After labelling with the corresponding antibodies, the percentages of macrophages-monocytes, B and T lymphocytes, thrombocytes and epithelial and endothelial cells were quantified by flow cytometry. The percentage of labelled cells $(a)$ and the percentage of labelled infected cells $(b)$ are represented. All negative responses were scored at $0.001 \%$. The medians are represented by a red dash. Asymptotic two-sample Fisher-Pitman permutation tests (one-way test) were performed (R software). Significance was ${ }^{*} p<0.05$.

Table 1. Percentages of infected cells (labelled and unlabelled) according to the organ.

\begin{tabular}{|c|c|c|c|c|}
\hline & $\begin{array}{l}\text { spleen } \\
\text { median (Q1; Q3) }\end{array}$ & $\begin{array}{l}\text { liver } \\
\text { median (Q1; Q3) }\end{array}$ & $\begin{array}{l}\text { aortic vessels } \\
\text { median (Q1; Q3) }\end{array}$ & $\begin{array}{l}\text { gall bladder } \\
\text { median (Q1; Q3) }\end{array}$ \\
\hline WT & $0.35(0.19 ; 0.53)$ & $0.07(0.06 ; 0.10)$ & $0.64(0.42 ; 2.49)$ & $2.23(1.54 ; 2.82)$ \\
\hline$\triangle i n v A$ & $0.19(0.14 ; 0.55)$ & $0.06(0.04 ; 0.16)$ & $0.21(0.12 ; 1.46)$ & $1.00(0.52 ; 2.71)$ \\
\hline $3 \Delta$ & $0.31(0.26 ; 0.38)$ & $0.06(0.04 ; 0.16)$ & $2.18(1.18 ; 2.54)$ & $3.65(2.39 ; 4.62)$ \\
\hline
\end{tabular}

material, table S1). Immune cells were highly infected. For example, about $10 \%$ of the $\mathrm{B}$ and $\mathrm{T}$ lymphocytes were infected by the different strains. Moreover, the gall bladder $\mathrm{B}$ and $\mathrm{T}$ lymphocytes were found to be infected more than in the other organs. The other identified cells were infected between $1 \%$ and $10 \%$ (figure $6 \mathrm{~b}$ ). In all cases except one, no statistical differences were observed between the chicks inoculated with the wild-type or the mutant strains. The only significant difference was observed for the infected monocytes-macrophages between the chicks infected with the wild-type strain and those infected with the inv $A$ mutant strain ( $p=0.020$; electronic supplementary material, table S1). This could be due to the fact that only two $\Delta$ invA-inoculated animals had infected monocytes-macrophages, while the percentages of monocytes-macrophages were similar for the five animals tested. Another interesting point is that the analyses of the infected areas (labelled + unlabelled) highlighted the high cell invasion rates of the gall bladder (table 1). Combining all experiments, after 2 days of infection, the median percentages of all infected cells (labelled and unlabelled) in the gall bladder were $2.23 \%, 1 \%$ and $3.65 \%$ depending on the strain inoculated, whereas in the spleen, for example, they were only $0.35 \%$, $0.19 \%$ and $0.31 \%$.

As this organ has never previously been described as a site of Salmonella colonization in chicks and as it is described as an organ that is important for Salmonella persistence in mice and humans $[65,66]$, we decided to observe the infected tissues using immunohistochemistry. Microscopic analysis shows that bacteria were located in the mucosa of the gall bladder including in the epithelium but also in the lamina propria, whatever the strain inoculated. Interestingly, when high numbers of Salmonella were detected the epithelium was damaged, while the structure of the gall bladder was well conserved when the tissue was only infected by a few bacteria (figure 7). 


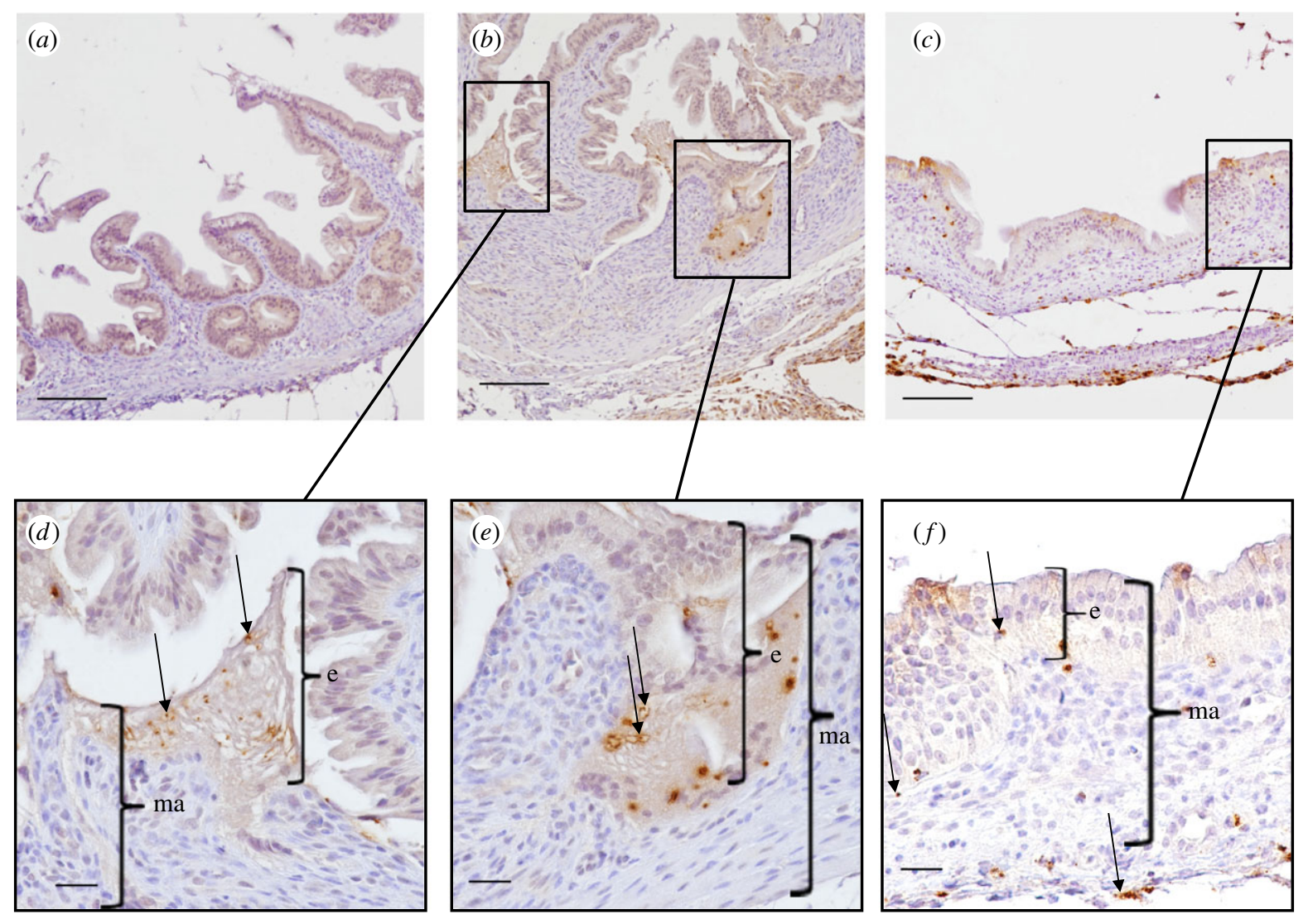

Figure 7. Immunohistochemistry of chick gall bladder infected with S. Typhimurium wild-type stain or with a mutant deleted of the three known invasion factors 5-day-old chicks were inoculated in the coelomic cavity with around $6 \times 10^{7}$ CFU per chick with S. Typhimurium 14028 turboFP650 wild-type strain (WT) or the

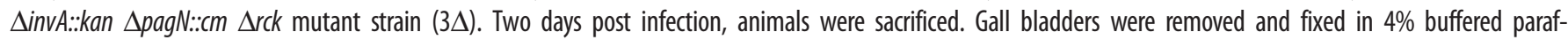
ormaldehyde at $4^{\circ} \mathrm{C}$ for $24 \mathrm{~h}$. Tissues were processed using routine methods, paraffin embedded, cut in sections (thickness, $5 \mu \mathrm{m}$ ) and stained with diaminobenzidine for IHC with HRP detection. The primary antibody was a rabbit anti-Salmonella 0:4,5 lipopolysaccharide marker. Tissues were examined and photographed with a light microscope Eclipse 80i, Nikon with DXM 1200C digital camera (Nikon Instruments, Europe, Amsterdam, The Netherlands) and NISElements D Microscope Imaging Software. Tissues were counterstained in blue with Harris's haematoxylin and Salmonella were stained in brown with HRP detection. Representative pictures are presented. Bacteria are seen $(\rightarrow)$ within the epithelium (e) and the mucosa (ma). Sections of a gall bladder of $(a)$ an uninfected chick, $(b, d, e)$ a chick infected by the wild-type strain and $(c, f)$ a chick infected by the $3 \Delta$ mutant are represented. Scale bar, $100 \mu \mathrm{m}$ in $(a-c)$ and $20 \mu \mathrm{m}$ in $(d-f)$.

The gall bladder is thus colonized by Salmonella after chicks are inoculated via an intracoelomic route. These results show that oral inoculation of Salmonella is not necessary for gall bladder infection. The bacteria reached the gall bladder through the vasculature or the ducts that emanate from the liver. Menendez et al. [67] obtained similar results in a mouse infection model. Indeed, they demonstrated that gallbladder colonization was not the result of Salmonella ascending directly from the gastrointestinal tract and their histological analyses supported the idea that bacteria were discharged from the liver into the gall bladder via the bile. Concerning the infected cells in the chick gall bladder, monocytes-macrophages, B and T lymphocytes, thrombocytes and epithelial cells of this organ were all infected at a relatively high level compared to the other organs and epithelial cells were the most infected cell type. Menendez et al. [67] also observed in their mouse model that Salmonella localized preferentially within epithelial cells of the gallbladder. However, bacteria were rarely seen within the lamina propria. Our observations of some S. Typhimurium in the mucosa and submucosa and the identification of infected monocytes-macrophages, $\mathrm{B}$ and $\mathrm{T}$ lymphocytes and thrombocytes demonstrate that epithelial cells are not the only cells infected in the gall bladder of chicks. Whether this result is restricted to chicks remains to be determined. Our results on our mutant strains also differ from those of Menendez et al. [67]. Indeed, our mutants were shown to infect similar cells to the wild-type, while Menendez et al. did not observe their invA mutant in the epithelial cells of the murine gall bladder, in contrast to their wild-type strain, suggesting that the T3SS- 1 is required for Salmonella colonization of the gall bladder in mice but not in chicks.

The gall bladder is known to be an organ in which S. Typhi persist during chronic infections in humans, after forming a biofilm on gallstones [40,66,68]. Models of chronic infection in mice have also been studied $[65,67,69]$. In guinea pigs, although asymptomatic, Salmonella could be recovered in the gall bladder for up to five months post infection [70]. However, in chicken it is not known whether this organ could be relevant for the persistence of Salmonella.

\subsection{Salmonella Typhimurium is able to persist in the gall bladder independently of the T3SS1, Rck and PagN}

As the previous results demonstrated that bacterial concentrations in the gall bladder were significant (figure 1) and 
(a) spleen

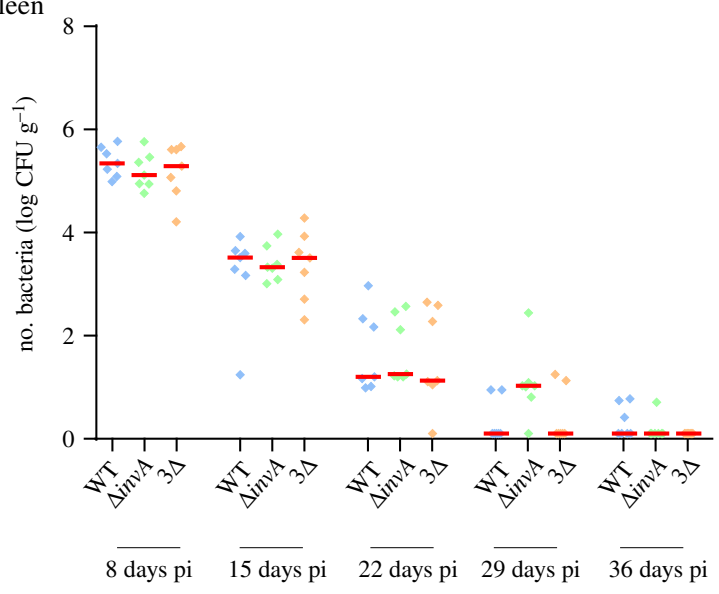

(b) gall bladder

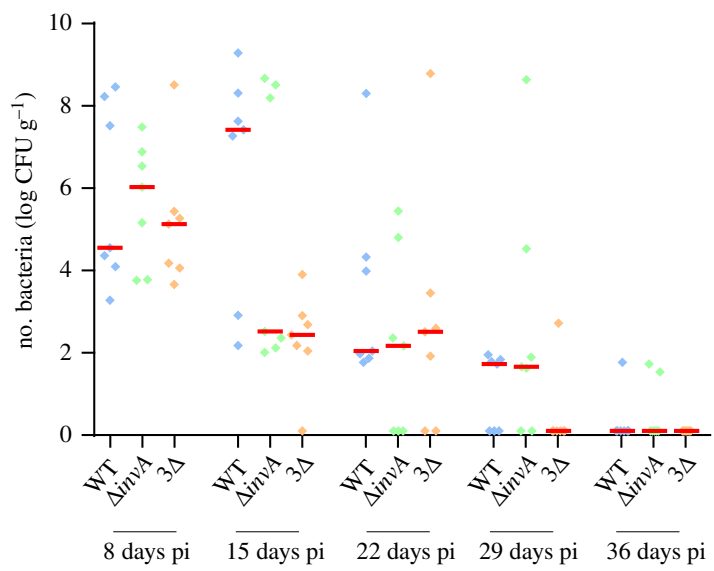

Figure 8. Persistence of S. Typhimurium in the spleen and in the gall bladder after intracoelomic inoculation. Five-day-old chicks were inoculated in the coelomic cavity with around $3 \times 10^{7} \mathrm{CFU}$ per chick with $\mathrm{S}$. Typhimurium 14028 turboFP650 wild-type (WT; blue diamond), $\Delta$ invA::kan mutant strain ( $\triangle$ invA; T3SS-1 defective; green diamond) or the $\triangle i n v A$ ::kan $\Delta$ pagN::cm $\Delta$ rck mutant strain (3 $\Delta$; T3SS-1, Rck, PagN defective; yellow diamond). Each week, seven animals were sacrificed and their spleens and gall bladders removed. The kinetics of spleen $(a)$ and gall bladder $(b)$ colonization were monitored each week for a period of 36 days. Results are expressed as number of bacteria (log CFU per gram of organ). The medians are represented by a red dash. A Kruskal-Wallis test was conducted, followed by a Dunn's multiple comparisons test (GraphPad Software). Significance was ${ }^{*} p<0.05$.

that Salmonella was able to infect several cell types in this organ, we verified whether this organ could be infected over the long term. To determine persistence, we infected chicks and monitored their colonization rate in the spleen and gall bladder for 36 days with slaughtering every 8 days. Bacteria were detected throughout the kinetics. No statistical differences of colonization could be observed in the spleen (figure $8 a$ ) or in the gall bladder (figure $8 b$ ), whatever the strain inoculated and the week of analysis. This work demonstrates for the first time that Salmonella Typhimurium could invade the gall bladder of chicks at levels and durations similar to those observed in the spleen and thus, can be considered as a site of colonization in addition to the spleen and the liver in chicks. In mice, during chronic infection, mimicking human $S$. Typhi infection, the spleen and the gall bladder are considered as organs of persistence and gall bladder colonization presumably leads to reinfection of the intestine through bile secretion $[39,54,65]$. Our results also demonstrate that for the gall bladder to be infected an oral route of infection is not necessary, as demonstrated by Menendez et al. [67] in a mouse model. The role of colonization of this organ needs to be analysed further, particularly regarding intestinal colonization and persistence of Salmonella.

\section{Conclusion and opening up}

This work demonstrates for the first time, that $S$. Typhimurium can invade in vivo a large array of phagocytic and nonphagocytic cells of different organs and vessels in chicks. These cells are immune cells but also epithelial and endothelial cells as previously demonstrated in vitro with cell lines [31]. Moreover, numerous unidentified cells were infected. This is explained by the lack of antibodies in chicken to identify among others, dendritic cells, fibroblasts and heterophils, which are also important for the spread of bacteria [54,71,72]. Therefore, new antibodies need to be developed for further studies in chicks. Nevertheless, our results show a great difference between mice and chicks. In mice, phagocytic cells and especially macrophages are the main cells in which Salmonella replicate in the liver and spleen [49-51,54]. In chicks, cell tropism in these organs, and also in the gall bladder and vessels, is more diverse with Salmonella being found intracellularly not only in monocytes-macrophages but also in lymphocytes, and endothelial and epithelial cells. Interestingly, endothelial cells from sinusoid capillaries (spleen and liver) were targeted by Salmonella, while endothelial cell invasion into continuous capillaries (vessels) was less clear and remains to be confirmed. Whether macrophages are or not the privileged localization of Salmonella in organs other than the liver and spleen in mice remains to be determined. Chicken cells infected in the gastrointestinal tract by Salmonella were not studied in this paper despite the relevance of this organ in Salmonella infection. This was due to serious experimental difficulties encountered including the auto-fluorescence of intestinal cells. Work is currently in progress to overcome these problems.

Even if Salmonella are able to invade numerous cells, specificity exists depending on the organ. Indeed, for example, during Salmonella infection in chicks, epithelial cells appear more sensitive in the gall bladder than in the liver. Similarly, endothelial cells appear more sensitive in the spleen than in the aortic vessels.

Surprisingly, the two mutant strains used in this study (i.e. a T3SS-1 mutant strain and a mutant strain defective for the three currently known invasion factors) were able to invade the same host cells as the wild-type strain. The fact that the triple mutant strain entered numerous host cells, in vivo, confirms our previous results suggesting the existence of unknown invasion factors [31]. However, we cannot conclude that the T3SS-1, PagN and Rck are not required for the invasion of chicken cells as a redundant role of the different invasion factors may occur. These two hypotheses are reinforced by our results of chicken infection demonstrating that chicks can be colonized at a higher level by the two mutant strains than by their wild-type parent after bacterial inoculation in the coelomic cavity. The absence of T3SS-1 requirement for chicken colonization has already been observed [18-20] and this fact can now be extended to the PagN and Rck invasins. However, in order to demonstrate whether or not these entry factors are redundant, further 
studies are necessary in chicks and other animals. Altogether, these results are important in understanding the mechanisms of Salmonella pathogenesis, as previous work has described that both bacterial behaviour and host response are different [28] depending on the entry mechanism, and thus this opens up new avenues of research. It raises the question as to whether possible unknown bacterial factors are required for cell invasion of systemic sites in chicken and, if this is the case, whether in vivo certain cell types are infected by a particular entry mechanism. It also questions whether the known invasion factors in chicks can replace each other. Finally, the fact that cells can be infected through multiple pathways in an organ suggests that their response could be multiple. Further studies involving Tnseq-mutant library screenings and single cell approaches would help to address these questions.

In conclusion, this paper demonstrates that $S$. Typhimurium infects numerous phagocytic and non-phagocytic cells in the spleen, liver and vessels of chicks. Cell invasion of the chick gall bladder was also observed for the first time. Monocytes-macrophages, B and T lymphocytes, thrombocytes and epithelial cells of this organ were all infected and at higher cell invasion rates than the other organs. Moreover, invasion of these cells occurs even in the absence of the three entry factors already identified whatever the organ. In line with these results, $S$. Typhimurium was shown to persist in the gall bladder of chicks independently of the three known invasion factors.

Data accessibility. All the data of flow cytometry, immuno-histochemistry and confocal microscopy have been deposited in the data repository Data INRAE at https://doi.org/10.15454/OEG7WH.

The data are provided in the electronic supplementary material [73].

Competing interests. We declare we have no competing interests. Funding. This work was supported by funding from the European Union's Horizon 2020 Research and Innovation programme under grant agreement no. 773830: One Health European Joint Programme on Monitoring the gut Microbiota and Immune Response to Predict, Prevent and Control zoonoses in humans and livestock in order to minimize the use of antimicrobials (MoMIR-PPC) https://onehealthejp.eu/jrp-momir/. A.R. held an INRA/Region Centre doctoral fellowship.

Acknowledgements. We would like to thank Jérôme Trotereau (SPVB, ISP unit, INRAE Val de Loire), who participated in inoculating the chicks, and the staff of the Experimental Platform for Infectious Diseases of Institut National de Recherche pour l'Agriculture, l'Alimentation et l'Environnement (PFIE, INRAE Val de Loire) for caring for the chicks and participating in the experiments, and also P. Quéré (3IMo, ISP unit, INRAE Val de Loire) for her advice on the labelling of the monocytes-macrophages. We are also grateful to T. Larcher (PAnTher APEX, INRAE-Oniris Nantes) for his advice and technical support.

\section{References}

1. WHO. 2017 WHO estimates of the global burden of foodborne diseases. See https://apps.who.int/iris/ handle/10665/199350.

2. ECDC Ea. 2019 The European Union summary report on trends and sources of zoonoses, zoonotic agents and food-borne outbreaks in 2016. EFSA J. 15, 5077. (doi:10.2903/j.efsa.2010.1496)

3. Ferrari RG, Rosario DKA, Cunha-Neto A, Mano SB, Figueiredo EES, Conte-Junior CA. 2019 Worldwide epidemiology of Salmonella serovars in animalbased foods: a meta-analysis. Appl. Environ. Microbiol. 85, e00591-19. (doi:10.1128/AEM. 00591-19)

4. Rabinowitz PM, Conti LA. 2009 Human-clinicalmedicine: clinical approaches to zoonoses, toxicants and other shared health risks. 1st edn. Maryland Heights, MD: Saunders.

5. Knight-Jones TJ, Mylrea GE, Kahn S. 2010 Animal production food safety: priority pathogens for standard setting by the World Organisation for Animal Health. Rev. Sci. Technol. 29, 523-535. (doi:10.20506/rst.29.3.1994)

6. Menanteau $P$, Kempf F, Trotereau J, VirlogeuxPayant I, Gitton E, Dalifard J, Gabriel I, Rychlik I, Velge P. 2018 Role of systemic infection, cross contaminations and super-shedders in Salmonella carrier state in chicken. Environ. Microbiol. 20, 3246-3260. (doi:10.1111/1462-2920.14294)

7. Ly KT, Casanova JE. 2007 Mechanisms of Salmonella entry into host cells. Cell. Microbiol. 9, 2103-2111. (doi:10.1111/j.1462-5822.2007.00992.x)

8. Heffernan E, Wu L, Louie J, Okamoto $S$, Fierer J, Guiney DG. 1994 Specificity of the complement resistance and cell association phenotypes encoded by the outer membrane protein genes $r c k$ from Salmonella Typhimurium and ail from Yersinia enterocolitica. Infect. Immun. 62, 5183-5186. (doi:10.1128/iai.62.11.5183-5186.1994)

9. Rosselin M et al. 2010 Rck of Salmonella enterica, subspecies enterica serovar Enteritidis, mediates zipper-like internalization. Cell Res. 20, 647-664. (doi:10.1038/cr.2010.45)

10. Lambert MA, Smith SG. 2008 The PagN protein of Salmonella enterica serovar Typhimurium is an adhesin and invasin. BMC Microbiol. 8, 142. (doi:10. 1186/1471-2180-8-142)

11. Lambert MA, Smith SG. 2009 The PagN protein mediates invasion via interaction with proteoglycan. FEMS Microbiol. Lett. 297, 209-216. (doi:10.1111/j. 1574-6968.2009.01666.x)

12. Wiedemann $A$ et al. 2016 Identification of the epidermal growth factor receptor as the receptor for Salmonella Rck-dependent invasion. FASEB J. 30, 4180-4191. (doi:10.1096/fj.201600701R)

13. Wallis TS, Galyov EE. 2000 Molecular basis of Salmonella-induced enteritis. Mol. Microbiol. 36, 997-1005. (doi:10.1046/j.1365-2958.2000. 01892.x)

14. Ineid B, Moreau K, Plaisance M, Rouaix A, Dano J, Simon S. 2016 Role of T3SS-1 SipD protein in protecting mice against non-typhoidal Salmonella Typhimurium. PLoS Negl. Trop. Dis. 10, e0005207. (doi:10.1371/journal.pntd.0005207)

15. Galan JE, Curtiss 3rd R. 1989 Cloning and molecular characterization of genes whose products allow Salmonella Typhimurium to penetrate tissue culture cells. Proc. Natl Acad. Sci. USA 86, 6383-6387. (doi:10.1073/pnas.86.16.6383)

16. Murray RA, Lee CA. 2000 Invasion genes are not required for Salmonella enterica serovar Typhimurium to breach the intestinal epithelium: evidence that Salmonella pathogenicity island 1 has alternative functions during infection. Infect. Immun. 68, 5050-5055. (doi:10.1128/IAl.68.9.50505055.2000)

17. Hapfelmeier $S$ et al. 2005 The Salmonella pathogenicity island (SPI)-2 and SPI-1 type III secretion systems allow Salmonella serovar Typhimurium to trigger colitis via MyD88dependent and MyD88-independent mechanisms. J. Immunol. 174, 1675-1685. (doi:10.4049/ jimmunol.174.3.1675)

18. Sivula CP, Bogomolnaya LM, Andrews-Polymenis HL. 2008 A comparison of cecal colonization of Salmonella enterica serotype Typhimurium in white leghorn chicks and Salmonella-resistant mice. BMC Microbiol. 8, 182. (doi:10.1186/14712180-8-182)

19. Rychlik I et al. 2009 Virulence potential of five major pathogenicity islands (SPI-1 to SPI-5) of Salmonella enterica serovar Enteritidis for chickens. BMC Microbiol. 9, 268. (doi:10.1186/14712180-9-268)

20. Desin TS, Lam PK, Koch B, Mickael C, Berberov E, Wisner AL, Townsend HGG, Potter AA, Köster W. 2009 Salmonella enterica serovar Enteritidis pathogenicity island 1 is not essential for but facilitates rapid systemic spread in chickens. Infect. Immun. 77, 2866-2875. (doi:10.1128/IAl.00039-09) 
21. Hu Q, Coburn B, Deng W, Li Y, Shi X, Lan Q, Wang B, Coombes BK, Finlay BB. 2008 Salmonella enterica serovar Senftenberg human clinical isolates lacking SPI-1. J. Clin. Microbiol. 46, 1330-1336. (doi:10. 1128/JCM.01255-07)

22. Suez J et al. 2013 Virulence gene profiling and pathogenicity characterization of non-typhoidal Salmonella accounted for invasive disease in humans. PLOS ONE 8, e58449. (doi:10.1371/journal. pone.0058449)

23. Conner $C P$, Heithoff $D M$, Julio $S M$, Sinsheimer RL, Mahan MJ. 1998 Differential patterns of acquired virulence genes distinguish Salmonella strains. Proc. Natl Acad. Sci. USA 95, 4641-4645. (doi:10.1073/ pnas.95.8.4641)

24. Dyszel JL, Smith IN, Lucas DE, Soares JA, Swearingen MC, Vross MA, Young GM, Ahmer BMM. 2010 Salmonella enterica serovar Typhimurium can detect acyl homoserine lactone production by Yersinia enterocolitica in mice. J. Bacteriol. 192, 29-37. (doi:10.1128/JB.01139-09)

25. Ghosh S, Chakraborty K, Nagaraja T, Basak S, Koley H, Dutta S, Mitra U, Das S. 2011 An adhesion protein of Salmonella enterica serovar Typhi is required for pathogenesis and potential target for vaccine development. Proc. Natl Acad. Sci. USA 108, 3348-3353. (doi:10.1073/pnas. 1016180108)

26. Tundup S, Kandasamy M, Perez JT, Mena N, Steel J, Nagy T, Albrecht RA, Manicassamy B. 2017 Endothelial cell tropism is a determinant of H5N1 pathogenesis in mammalian species. PLoS Pathog. 13, e1006270. (doi:10.1371/journal.ppat. 1006270)

27. Pereira SS, Trindade S, De Niz M, Figueiredo LM. 2019 Tissue tropism in parasitic diseases. Open Biol. 9, 190036. (doi:10.1098/rsob.190036)

28. Miao EA, Mao DP, Yudkovsky N, Bonneau R, Lorang CG, Warren SE, Leaf IA, Aderem A. 2010 Innate immune detection of the type III secretion apparatus through the NLRC4 inflammasome. Proc. Natl Acad. Sci. USA 107, 3076-3080. (doi:10.1073/ pnas.0913087107)

29. Valdivia RH, Falkow S. 1996 Bacterial genetics by flow cytometry: rapid isolation of Salmonella Typhimurium acid-inducible promoters by differential fluorescence induction. Mol. Microbiol. 22, 367-378. (doi:10.1046/j.1365-2958.1996. 00120.x)

30. Casadaban MJ, Cohen SN. 1980 Analysis of gene control signals by DNA fusion and cloning in Escherichia coli. J. Mol. Biol. 138, 179-207. (doi:10. 1016/0022-2836(80)90283-1)

31. Roche SM, Holbert $S$, Trotereau J, Schaeffer $S$, Georgeault S, Virlogeux-Payant I, Velge P. 2018 Salmonella Typhimurium invalidated for the three currently known invasion factors keeps its ability to invade several cell models. Front. Cell Infect. Microbiol. 8, 273. (doi:10.3389/fcimb.2018.00273)

32. Mast J, Goddeeris BM, Peeters K, Vandesande F, Berghman LR. 1998 Characterisation of chicken monocytes, macrophages and interdigitating cells by the monoclonal antibody KUL01. Vet. Immunol.
Immunopathol. 61, 343-357. (doi:10.1016/501652427(97)00152-9)

33. Chen CL, Ager LL, Gartland GL, Cooper MD. 1986 Identification of a $T 3 / T$ cell receptor complex in chickens. J. Exp. Med. 164, 375-380. (doi:10.1084/ jem.164.1.375)

34. Rothwell U, Vervelde L, Davison TF. 1996 Identification of Bu-1 alloantigens using the monoclonal antibody AV20. In Poultry immunology. Abindon, UK: Carfax.

35. Lacoste-Eleaume AS, Bleux C, Quere P, Coudert F, Corbel C, Kanellopoulos-Langevin C. 1994 Biochemical and functional characterization of an avian homolog of the integrin GPIllb-Illa present on chicken thrombocytes. Exp. Cell Res. 213, 198-209. (doi:10.1006/excr.1994.1191)

36. Gallin WJ, Edelman GM, Cunningham BA. 1983 Characterization of L-CAM, a major cell adhesion molecule from embryonic liver cells. Proc. Natl Acad. Sci. USA 80, 1038-1042. (doi:10.1073/ pnas.80.4.1038)

37. Virlogeux-Payant I, Mompart F, Ph V, Bottreau E, Pardon P. 2003 Low persistence of a largeplasmid-cured variant of Salmonella Enteritidis in ceca of chicks. Avian Dis. 47, 163. (doi:10.1637/ 0005-2086(2003)047[0163:LPOALP]2.0.C0;2)

38. Withanage GSK et al. 2004 Rapid expression of chemokines and proinflammatory cytokines in newly hatched chickens infected with Salmonella enterica serovar Typhimurium. Infect. Immun. 72, 2152. (doi:10.1128/IAl.72.4. 2152-2159.2004)

39. Gonzalez-Escobedo G, Gunn JS. 2013 Gallbladder epithelium as a niche for chronic Salmonella carriage. Infect. Immun. 81, 2920-2930. (doi:10. 1128/IAl.00258-13)

40. Gonzalez-Escobedo G, Marshall JM, Gunn JS. 2011 Chronic and acute infection of the gall bladder by Salmonella Typhi: understanding the carrier state. Nat. Rev. Microbiol. 9, 9-14. (doi:10.1038/ nrmicro2490)

41. Galan JE. 2001 Salmonella interactions with host cells: type III secretion at work. Annu. Rev. Cell Dev. Biol. 17, 53-86. (doi:10.1146/annurev.cellbio. 17.1.53)

42. Coburn B, Sekirov I, Finlay BB. 2007 Type III secretion systems and disease. Clin. Microbiol. Rev. 20, 535-549. (doi:10.1128/CMR.00013-07)

43. McGhie EJ, Brawn LC, Hume PJ, Humphreys D, Koronakis V. 2009 Salmonella takes control: effectordriven manipulation of the host. Curr. Opin. Microbiol. 12, 117-124. (doi:10.1016/j.mib.2008. 12.001)

44. Pavlova B, Volf J, Ondrackova P, Matiasovic J, Stepanova H, Crhanova M, Karasova D, Faldyna M, Rychlik I. 2011 SPI-1-encoded type III secretion system of Salmonella enterica is required for the suppression of porcine alveolar macrophage cytokine expression. Vet. Res. 42, 16. (doi:10.1186/ 1297-9716-42-16)

45. Sekirov I, Gill N, Jogova M, Tam N, Robertson M, de Llanos R, Li Y, Finlay BB. 2010 Salmonella SPI-1mediated neutrophil recruitment during enteric colitis is associated with reduction and alteration in intestinal microbiota. Gut Microbes 1, 30-41. (doi:10.4161/gmic.1.1.10950)

46. Zhao $X$ et al. 2018 Biochanin a enhances the defense against Salmonella enterica infection through AMPK/ULK1/mTOR-mediated autophagy and extracellular traps and reversing SPI-1dependent macrophage (MPhi) M2 polarization. Front. Cell Infect. Microbiol. 8, 318. (doi:10.3389/ fcimb.2018.00318)

47. Lou L, Zhang P, Piao R, Wang Y. 2019 Salmonella Pathogenicity Island 1 (SPI-1) and its complex regulatory network. Front. Cell Infect. Microbiol. 9, 270. (doi:10.3389/fcimb.2019.00270)

48. Elsheimer-Matulova M, Varmuzova K, Kyrova K, Havlickova H, Sisak F, Rahman M, Rychlik I. 2015 phoP, SPI1, SPI2 and aroA mutants of Salmonella Enteritidis induce a different immune response in chickens. Vet. Res. 46, 96. (doi:10.1186/s13567-015-0224-x)

49. Richter-Dahlfors A, Buchan AM, Finlay BB. 1997 Murine salmonellosis studied by confocal microscopy: Salmonella Typhimurium resides intracellularly inside macrophages and exerts a cytotoxic effect on phagocytes in vivo. J. Exp. Med. 186, 569-580. (doi:10.1084/jem.186.4.569)

50. Salcedo SP, Noursadeghi M, Cohen J, Holden DW. 2001 Intracellular replication of Salmonella Typhimurium strains in specific subsets of splenic macrophages in vivo. Cell. Microbiol. 3, 587-597. (doi:10.1046/j.1462-5822.2001.00137.x)

51. Sheppard M, Webb C, Heath F, Mallows V, Emilianus R, Maskell D, Mastroeni P. 2003 Dynamics of bacterial growth and distribution within the liver during Salmonella infection. Cell. Microbiol. 5, 593-600. (doi:10.1046/j.1462-5822.2003.00296.x)

52. Geddes K, Cruz F, Heffron F. 2007 Analysis of cells targeted by Salmonella type III secretion in vivo. PLoS Pathog. 3, e196. (doi:10.1371/journal.ppat. 0030196)

53. Thone F, Schwanhausser B, Becker D, Ballmaier M, Bumann D. 2007 FACS-isolation of Salmonellainfected cells with defined bacterial load from mouse spleen. J. Microbiol. Methods 71, 220-224. (doi:10.1016/j.mimet.2007.08.016)

54. Watson KG, Holden DW. 2010 Dynamics of growth and dissemination of Salmonella in vivo. Cell. Microbiol. 12, 1389-1397. (doi:10.1111/j.14625822.2010.01511.x)

55. Mastroeni P, Grant A, Restif O, Maskell D. 2009 A dynamic view of the spread and intracellular distribution of Salmonella enterica. Nat. Rev. Microbiol. 7, 73-80. (doi:10.1038/nrmicro2034)

56. Jeurissen SH. 1991 Structure and function of the chicken spleen. Res. Immunol. 142, 352-355. (doi:10.1016/0923-2494(91)90090-6)

57. Fields PI, Swanson RV, Haidaris CG, Heffron F. 1986 Mutants of Salmonella Typhimurium that cannot survive within the macrophage are avirulent. Proc. Natl Acad. Sci. USA 83, 5189-5193. (doi:10.1073/ pnas.83.14.5189)

58. Zaefarian F, Abdollahi MR, Cowieson A, Ravindran V. 2019 Avian liver: the forgotten organ. Animals (Basel) 9, 63. (doi:10.3390/ani9020063) 
59. Hu T, Wu Z, Bush SJ, Freem L, Vervelde L, Summers KM, Hume DA, Balic A, Kaiser P. 2019 Characterization of subpopulations of chicken mononuclear phagocytes that express TIM4 and CSF1R. J. Immunol. 202, 1186-1199. (doi:10.4049/ jimmunol.1800504)

60. Mehal WZ, Azzaroli F, Crispe IN. 2001 Immunology of the healthy liver: old questions and new insights. Gastroenterology 120, 250-260. (doi:10.1053/gast. 2001.20947)

61. Wang Y, Zhang C. 2019 The roles of liver-resident lymphocytes in liver diseases. Front. Immunol. 10, 1582. (doi:10.3389/fimmu.2019.01582)

62. Erdogan S. 2012 The branching of the aortic arch in the Eurasian bittern (Botaurus stellaris, Linnaeus 1758). Vet. Med. 57, 239-244. (doi:10.17221/5954VETMED)

63. Tucker WD, Arora Y, Mahajan K. 2020 Anatomy, blood vessels. In Statpearls (internet). Treasure Island, FL: StatPearls Publishing.

64. Iqbal J, Bhutto AL, Shah MG, Lochi GM, Hayat S, Ali N, Khan T, Khan AM, Khan A. 2014 Gross anatomical and histological studies on the liver of broiler. J. Appl. Environ. Biol. Sci. 4, 284-295.
65. Crawford RW, Rosales-Reyes R, Ramirez-Aguilar Mde L, Chapa-Azuela 0, Alpuche-Aranda C, Gunn JS. 2010 Gallstones play a significant role in Salmonella spp. gallbladder colonization and carriage. Proc. Natl Acad. Sci. USA 107, 4353-4358. (doi:10.1073/pnas. 1000862107)

66. Di Domenico EG, Cavallo I, Pontone M, Toma L, Ensoli F. 2017 Biofilm producing Salmonella Typhi: chronic colonization and development of gallbladder cancer. Int. J. Mol. Sci. 18, 1887. (doi:10.3390/ijms18091887)

67. Menendez A, Arena ET, Guttman JA, Thorson L, Vallance BA, Vogl W, Finlay BB. 2009 Salmonella infection of gallbladder epithelial cells drives local inflammation and injury in a model of acute typhoid fever. J. Infect. Dis. 200, 1703-1713. (doi:10.1086/646608)

68. Gunn JS, Marshall JM, Baker S, Dongol S, Charles RC, Ryan ET. 2014 Salmonella chronic carriage: epidemiology, diagnosis, and gallbladder persistence. Trends Microbiol. 22, 648-655. (doi:10. 1016/j.tim.2014.06.007)

69. Scanu T et al. 2015 Salmonella manipulation of host signaling pathways provokes cellular transformation associated with gallbladder carcinoma. Cell Host Microbe 17, 763-774. (doi:10.1016/j.chom.2015. 05.002)

70. Lavergne GM, James HF, Martineau C, Diena BB, Lior H. 1977 The guinea pig as a model for the asymptomatic human typhoid carrier. Lab. Anim. Sci. 27(5 Pt 2), 806-816.

71. van Dijk A, Tersteeg-Zijderveld MH, Tjeerdsma-van Bokhoven JL, Jansman AJ, Veldhuizen EJ, Haagsman HP. 2009 Chicken heterophils are recruited to the site of Salmonella infection and release antibacterial mature Cathelicidin-2 upon stimulation with LPS. Mol. Immunol. 46, 1517-1526. (doi:10.1016/j. molimm.2008.12.015)

72. Aiastui A, Pucciarelli MG, Garcia-del Portillo F. 2010 Salmonella enterica serovar Typhimurium invades fibroblasts by multiple routes differing from the entry into epithelial cells. Infect. Immun. 78, 2700-2713. (doi:10.1128/IAl.01389-09)

73. Roche SM, Holbert S, Vern YL, Rossignol C, Rossignol A, Velge P, Virlogeux-Payant I. 2021 A large panel of chicken cells are invaded in vivo by Salmonella Typhimurium even when depleted of all known invasion factors. FigShare. 